\title{
Optical properties of Forel-Ule water types deduced from 15 years of global satellite ocean color observations
}

\author{
Jaime Pitarch ${ }^{1 *}$, Hendrik J. van der Woerd ${ }^{2}$, Robert J. W. Brewin ${ }^{3}$, Oliver Zielinski ${ }^{4,5}$ \\ ${ }^{1} \mathrm{NIOZ}$ Royal Netherlands Institute for Sea Research, Department of Coastal Systems, and \\ Utrecht University, PO Box 59, 1790AB Den Burg, Texel, The Netherlands \\ ${ }^{2}$ Institute for Environmental Studies (IVM), Water \& Climate Risk, VU University Amsterdam, \\ De Boelelaan 1087, 1081HV Amsterdam, The Netherlands \\ ${ }^{3}$ National Centre for Earth Observation, Plymouth Marine Laboratory, Prospect Place, PL1 3DH \\ Plymouth, United Kingdom \\ ${ }^{4}$ Center for Marine Sensors, Institute for Chemistry and Biology of the Marine Environment, \\ Carl von Ossietzky University of Oldenburg, Schleusenstrasse 1, 26382 Wilhelmshaven, Germany \\ ${ }^{5}$ DFKI Research Group Marine Perception, Marie Curie Strasse 1, 26129 Oldenburg, Germany \\ *jaime.pitarch@nioz.nl
}

\section{Abstract}

The Forel-Ule (FU) color comparator scale is the oldest set of optical water types (OWTs). This scale was originally developed for visual comparison and generated an immense amount of data, with hundreds of thousands of observations being gathered from the last 130 years. Since recently, the FU scale is also applicable to remote sensing data. This has been possible thanks to an optical characterization of the $21 \mathrm{FU}$ colors in terms of the $(x, y)$ CIE standards and new algorithms that convert remote-sensing reflectances $\left(R_{r s}\right)$ from satellite-borne ocean color sensors to $F U$. $R_{r s}$-derived hue angle and FU have been recently applied with success in the assessment of color variability of lakes and specific shelf areas, but an evaluation over global oceanic waters is still missing. By clustering global climatological ESA-OC-CCI v2.0 $\mathrm{R}_{\mathrm{rs}}$ with the derived FU, we obtain a set of $\mathrm{R}_{\mathrm{rs}}$ to be used as optical water types (OWTs). Diffuse attenuation coefficient, Secchi disk depth and chlorophyll concentration are also associated to the FU classes. The angular distances of a given $\mathrm{R}_{\mathrm{rs}}$ to the two nearest FU classes are proposed as simple and robust membership indexes, adding up to one. We also evaluate the advantages and limitations of FU and the hue angle as monitoring tools over the full marine range, from the most oligotrophic areas to the turbid and productive coastal zones. The first $7 \mathrm{FU}$ indexes cover $99 \%$ of global surface waters. Unlike the hue angle, that resolves all spatiotemporal color variations, the FU scale is coarse as a monitoring tool for oligotrophic waters as all the subtropical gyres saturate to $\mathrm{FU}=1$, while the color of other seas varies across 2, 3 or even $4 \mathrm{FU}$ classes. We illustrate the introduction of a new "zero" FU class that increases monitoring resolution at the blue end of the color range. Finally, we show how optical diversity varies across the color range and compare several sets of OWTs from a color perspective. Overall, we provide a valuable and self-consistent dataset that enhances the usefulness of the FU scale by converting it to useful information for the oceanographic community. This OWT scheme keeps the advantages of other datasets, like being useful to study ocean color product quality and characterize the uncertainties, but also allows to continue to monitor long-term change in optical diversity over the global ocean color. Integration into the optical modules of ecosystem models can help verify past simulations that predate the satellite age, through comparisons with in-situ FU data collected at the time. 


\section{Introduction}

Classification of water masses into optical types has been an old practice in optical oceanography and the quantity used for classification has varied with the available technology. The first classification, the Forel-Ule scale (FU) (Forel 1890; Ule 1892), was developed as a visual color comparator originally conceived for inland waters, although soon after it also started to be used in sea water (Wernand et al. 2013b, and references therein). The FU scale is made of twenty-one colors across a hue gradient, from blue to green, yellow and brown (Novoa et al. 2013). Currently, more than 280000 observations over global marine areas are centralized by NOAA (https://www.nodc.noaa.gov/OC5/WOD/secchi-data-format.html) and constitute the longest record of ocean color archive, extending up to thirteen decades into the past. FU derived climatological maps show patterns consistent with our current understanding of the optics of the global oceans (Boyce et al. 2012; Wernand et al. 2013b). FU observations correlate well with in-situ chlorophyll until FU=10 (Boyce et al. 2012) and this principle was used to derive multi-decadal chlorophyll trends from in-situ FU observations (Wernand et al. 2013b).

Morel and Prieur (1977) defined the famous classification case 1 and case 2 waters, in terms of the relative amount of phytoplankton concentration and non-living material. This classification has been interpreted by many as a distinction between water where all optically-active constituents correlate to chlorophyll concentration and water where they do not (Lee and Hu 2006). In the last years, the term "case 2 " is being replaced by "optically complex", though keeping a similar interpretation.

Jerlov (1976) categorized waters into five oceanic and five coastal types based on diffuse attenuation coefficient $\left(K_{d}\right)$ spectra and provided maps of this classification from in-situ $K_{d}$ cruise data. The popularity of the Jerlov's optical water types (OWTs) across disciplines was facilitated by their description in terms of light attenuation, a quantity with a clear meaning for all oceanographers. Ecosystem modelers often parameterize light extinction by assuming a given Jerlov water type (Burchard et al. 1999; Cahill et al. 2008; Löptien et al. 2009). It is also widely used in the field of underwater optical communications (Kaushal and Kaddoum 2016). Solonenko and Mobley (2015) associated Jerlov's types to absorption and scattering coefficients in average marine waters after bio-optical modeling.

Moore's original OWTs (Moore et al. 2001) are based on remote-sensing reflectance $\left(R_{r s}\right)$ and have undergone modifications (Moore et al. 2009; Moore et al. 2012), being Jackson et al. (2017) the last update (J17 from hereon). Mélin and Vantrepotte (2015) (M15 from hereon) generated their OWTs from satellite $R_{r s}$ after removal of open oceanic waters, thus increasing the weight of optically complex waters, although their dataset also included very clear waters, thus making their classification arguably suitable for oceanic waters as well. Wei et al. (2016) developed a novel quality assurance system for in-situ and satellite $R_{r s}$. Its concept was that the quality of a given $R_{r s}$ needed to be defined not only after a per-band matchup analysis, but also by assessing the spectral shape. Therefore, they compiled in-situ $\mathrm{R}_{\mathrm{rs}}$ of a wide range of waters, from ultra-oligotrophic to eutrophic, yellow, shallow and sediment-rich waters, and clustered them in classes (W16 from hereon).

Other than for algorithm blending, uncertainty assessment and quality control, OWTs are useful as indicators of seasonal and geographical variability, linked to physical and biological processes (Trochta et al. 2015). There have been other published OWTs over inland water for specific areas, but we do not include them in this short review as this work focuses on global oceanic waters.

OWTs classification can only be applied to satellite data if the quantity used to classify can be derived remotely. Benefits of this approach are many, as satellite data provide unique spatial coverage and temporal frequency. Wernand et al. (2013a) presented an algorithm to calculate FU from MERIS $\mathrm{R}_{\mathrm{rs}}$. By using the hue angle as FU's continuous counterpart, FU can be derived using data from any satellite sensor where a hue angle algorithm is available (van der Woerd and Wernand 
2015, 2018). Based on these cited works, hue angle and FU processors were developed for the ESA SNAP software (http://step.esa.int/main/toolboxes/snap/). These algorithms have recently found application to study color variability of a large amount of New Zealand lakes using five years of Landsat 8 data (Lehmann et al. 2018), global inland waters using MODIS data for summer 2012 (Wang et al. 2018) and Mozambique and the Irish seas using twelve years of MODIS data (Jafar-Sidik et al. 2018). Dutkiewicz et al. (2019) incorporated an optical module to a global physics and biogeochemistry model and were able to predict $R_{r s}$ changes during the $21^{\text {st }}$ century, forced by a predicted scenario of green-house gas emissions. They applied the hue algorithm to the predicted $\mathrm{R}_{\mathrm{rs}}$ and found that the color of the oceans will change unevenly. They forecasted a bluer North Atlantic, with a hue angle increase of $\sim 10^{\circ}$ by 2100 , whereas other zones displayed smaller hue angle increases or decreases. Wang et al. (2019) presented a method to link combined Secchi disk depth and Forel-Ule data to absorption and backscattering, with the motivation to bridge the gap between historical and modern measurements in marine optics and build long time series, in a similar fashion as previously done using chlorophyll as the target variable (Boyce et al. 2012).

In this article, we apply the FU and hue angle algorithms to ocean color data over global marine waters, and study how seasonal variability of very diverse marine zones is resolved by them. We also provide quantification of the optical diversity of marine waters and quantify the uncertainty due to dimensionality reduction. We show that the FU scale can be interpreted as an OWTs set, by clustering all marine $\mathrm{R}_{\mathrm{rs}}$ falling into a given $\mathrm{FU}$ and obtaining the mean value. If the same procedure is followed for the $R_{r s}$-derived chlorophyll concentration $\left(C_{a}\right)$, as well as other IOPs and AOPs, a reliable translation of the FU colors into modern optical variables is obtained, with major importance for the interpretation of archived in-situ FU data, as well as for a rapid interpretation of marine $\mathrm{R}_{\mathrm{rs}}$ and FU data in terms of other optical variables.

The aims of this work are to:

- Develop a historical, FU-class based method, to study optical diversity at global scale.

- Construct a global dataset of matched FU class data with standard variables used by the oceanographic community.

- Monitor global variability of selected marine zones with the hue angle.

- Provide a new framework for comparison of different OWT schemes.
The approach is significant, as unlike other OWT schemes, the FU scale can be used to:

- Continue to monitor long-term change in optical diversity over the global ocean color by stitching together in situ FU data collected over the past century with the satellite era.

- Bridge, in a consistent manner, satellite data from two different periods (e.g. 1970-80's CZCS and 1997-onward) using in situ FU data over the two periods.

- Verify past model simulations that predate the satellite era, through comparison with in situ FU data collected at the time by using an optical module within the ecosystem model.

- Facilitate the interpretation of FU color by the oceanographic community, useful for teaching and demonstrating the concepts of satellite ocean color at global scale, using a visual index.

\section{Materials and Methods}

\subsection{Satellite data}

The most suited source data to study the global seasonal variability are climatological reflectances derived from a long time series. The ESA-OC-CCl v2.0 $\mathrm{R}_{\mathrm{rs}}$ monthly climatological dataset at 0.25 degrees was downloaded from the ftp server at of the ESA-OC-CCI site. These files are monthly composites (1997-2013) of merged sensor (MERIS, MODIS, SeaWiFS) products, where $\mathrm{R}_{\mathrm{rs}}$ from MODIS and MERIS were band-shifted and bias-corrected to SeaWiFS bands and values. MODIS and SeaWiFS $R_{\mathrm{rs}}$ products were derived from $4 \mathrm{~km}$ resolution level-3 binned standard NASA products; 
MERIS was derived from a $4 \mathrm{~km}$ level-3 binning of the output of the HYGEOS POLYMER algorithm. Downloadable NetCDF files include $R_{r s}$ available at the wavelengths $412,443,490,510,555$ and 670 $\mathrm{nm}$ as well as $C_{a}$. Notably, the files include pixel-by-pixel bias estimates of all variables. This allows to obtain unbiased monthly estimates of each. Further information on the generated $R_{r s}$ and $C_{a}$ products can be retrieved in the Product User Guide (Grant et al. 2015).

From the unbiased $R_{r s}$, the absorption ( $a$ ) and backscattering coefficient $\left(b_{b}\right)$ were retrieved using the QAA v6 algorithm (Lee et al. 2002) and the diffuse attenuation coefficient $\left(K_{d}\right)$ was derived from them (Lee et al. 2013). The Secchi disk depth was derived according to Lee et al. (2015). The derivations of the $\mathrm{CIE}(\mathrm{x}, \mathrm{y})$ coordinates, the hue angle and the $\mathrm{FU}$ index are explained in the next section.

\subsection{Reflectance conversion into color}

The FU scale was recently revisited, manufactured and optically characterized (Novoa et al. 2013). Derivation of the hue angle and the FU index from satellite data was recently presented as well (van der Woerd and Wernand 2015, 2018; Wernand et al. 2013a). We provide here a complete summary of the background needed in the article.

The calculations start with projecting a given spectrum $\left(R_{r s}\right.$ here) onto the CIE tristimulus space $(\mathrm{X}, \mathrm{Y}, \mathrm{Z})$ by weighting it with the three $\mathrm{CIE}$ standard observer color matching functions and integrating over the full range $\Lambda$ :

$$
X=\int_{\Lambda} R_{r s}(\lambda) \bar{x}(\lambda) d \lambda, Y=\int_{\Lambda} R_{r s}(\lambda) \bar{y}(\lambda) d \lambda, Z=\int_{\Lambda} R_{r s}(\lambda) \bar{z}(\lambda) d \lambda(1)
$$

These weighting functions are plotted in Fig. 1 . Their sum, $\bar{x}+\bar{y}+\bar{z}$, is also plotted. This plot illustrates the band range to which this algorithm is sensitive.

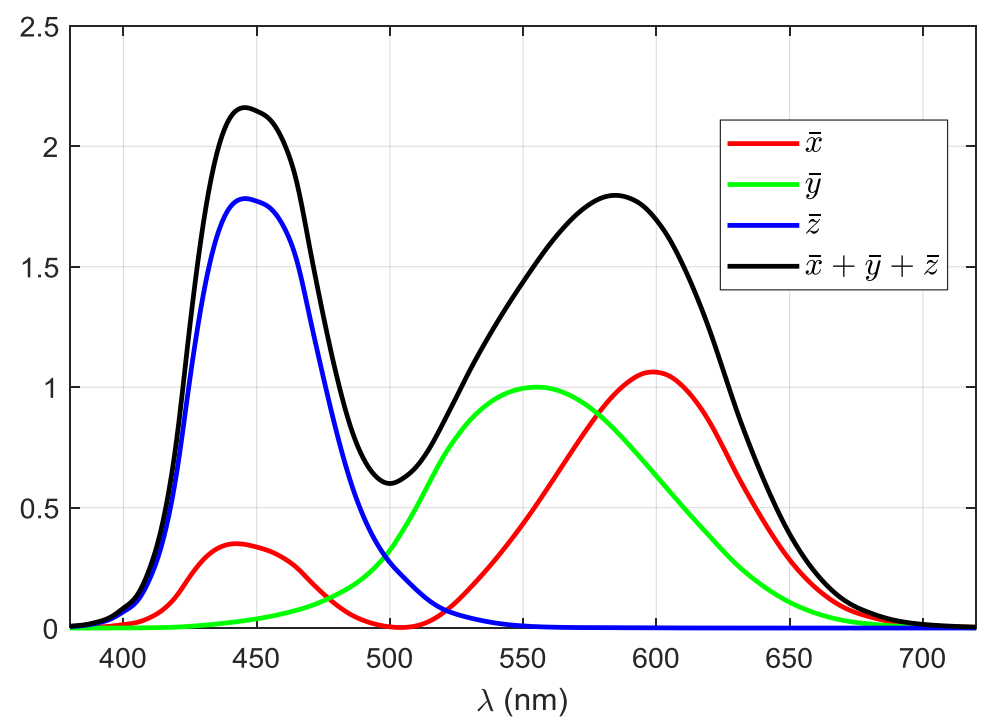

Fig. 1 The CIE standard observer color matching functions and the sum of all.

Equation (2) further reduces the dimensionality from three to two by normalizing the three quantities in eq. (1) by the sum of them. Information on the spectrum intensity or brightness is lost after this normalization. Therefore, a constant spectrum (white or gray) is projected onto $\left(x_{w}, y_{w}\right)=(1 / 3,1 / 3)$. (Jackson et al. 2017). Here, division by $(X+Y+Z)$ equals to a normalization by the sum of the three color matching functions, $\bar{x}+\bar{y}+\bar{z}$. Thus, two different $\mathrm{R}_{\mathrm{rs}}$ that differ by a constant factor would be projected onto the same $(x, y)$ point.

$$
x=\frac{X}{X+Y+Z}, y=\frac{Y}{X+Y+Z}
$$




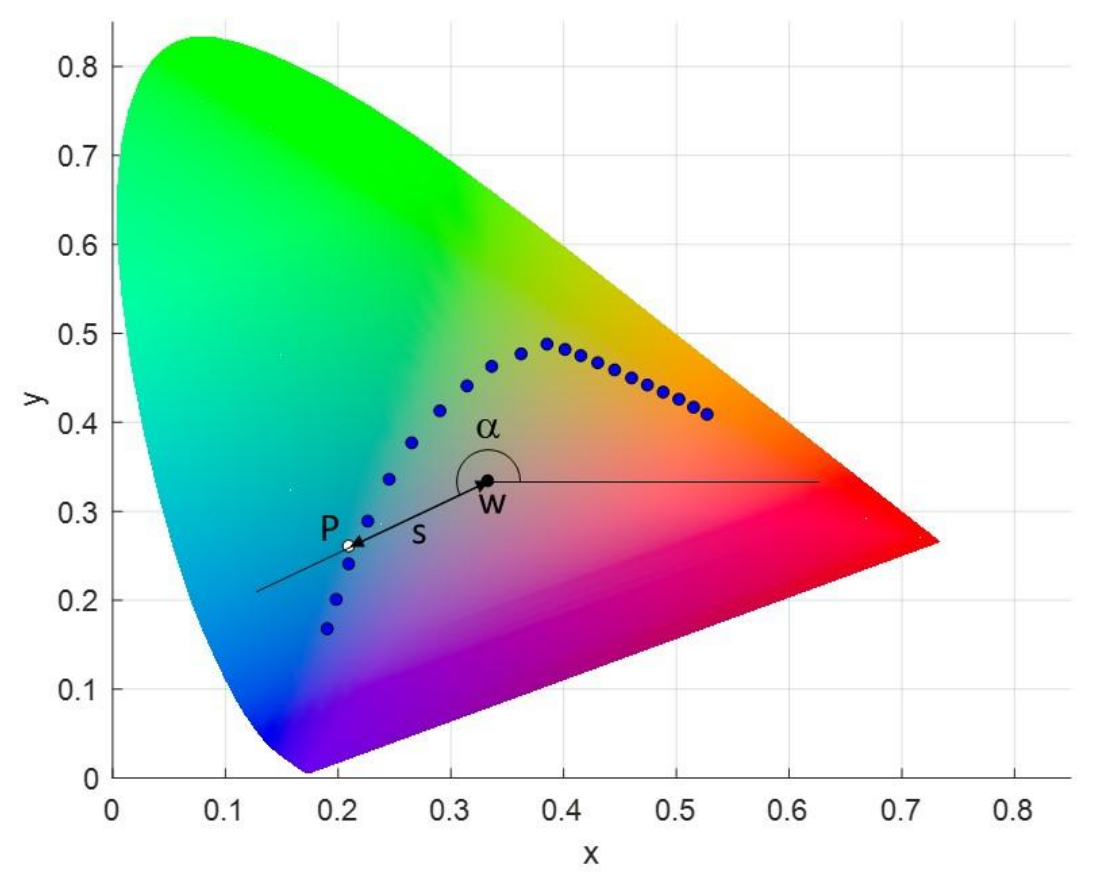

Fig. 2 The CIE 1931 color space in the $(x, y)$ coordinates. The coordinates of the $21 \mathrm{FU}$ colors after Novoa et al. (2013) are plotted as blue dots. The white point $W$ lays on $(1 / 3,1 / 3)$. An arbitrary spectrum is represented as point $P$, having polar coordinates $(\alpha, s)$ and laying between FU 3 and 4 .

Fig. 2 illustrates a given $R_{r s}$, projected onto the $(x, y)$ space as point $P$, following eqs. (1-2). The projection of a given $R_{r s}$ onto the $(x, y)$ coordinates is a great dimensionality reduction, but $(x, y)$ still contain information on the spectrum shape. Points close to the white point W (lower s) have a broader spectral shape, and the closer they get to it, the more the definition of color loses its meaning. On the other hand, points far away from $\mathrm{W}$ have a higher saturation or purity, and they are spectrally narrower. Thus, saturation $(s)$, and hue angle $(\alpha)$ can be separated by converting $(x, y)$ to polar coordinates, setting the origin at $\mathrm{W}$.

$$
\alpha=\arctan \left(\frac{y-y_{w}}{x-x_{w}}\right), s=\sqrt{\left(x-x_{w}\right)^{2}+\left(y-y_{w}\right)^{2}}
$$

As every FU index has its relative (x,y) coordinates after Novoa et al. (2013), the FU of any given spectrum is calculated as the nearest FU class in terms of the hue angle. As a matter of nomenclature, we refer to " $\mathrm{FU}_{\mathrm{n}}$ " as the n-th $\mathrm{FU}$ index of any of the 21 classes, whereas we write "FU=n" when a given spectrum is closest to $\mathrm{FU}_{\mathrm{n}}$ in terms of hue angle than to any other FU index.

In the practical implementation using satellite data, $R_{r s}$ is not a continuous spectrum but a set of discrete values as a result of the convolution with the sensor spectral response functions of each band. Van der Woerd and Wernand (2015) and van der Woerd and Wernand (2018) proposed a discretization of eq. (1) for the estimation of $X, Y$ and $Z$. In particular, for a $R_{r s}$ at the SeaWiFS bands, the discrete integration leads the following linear combination of the bands:

$$
\left(\begin{array}{l}
X \\
Y \\
Z
\end{array}\right)=\left(\begin{array}{cccccc}
2.957 & 10.861 & 3.744 & 3.455 & 52.304 & 32.825 \\
0.112 & 1.711 & 5.672 & 21.929 & 59.454 & 17.810 \\
14.354 & 58.356 & 28.227 & 3.967 & 0.682 & 0.018
\end{array}\right) R_{r s, s w}
$$

where $R_{r s, s w}$ is a column vector containing $R_{r s}$ at the SeaWiFS bands. From eq. (4), the $(x, y)$ coordinates and the hue angle can be obtained with eq. (2). Van der Woerd and Wernand (2015) and van der Woerd and Wernand (2018) showed that the discrete integration to estimate the hue angle contains an uncertainty that is only partially random, and has a rather predictable shape as a function of the estimated hue angle itself. This is a consequence of the generally smooth and 


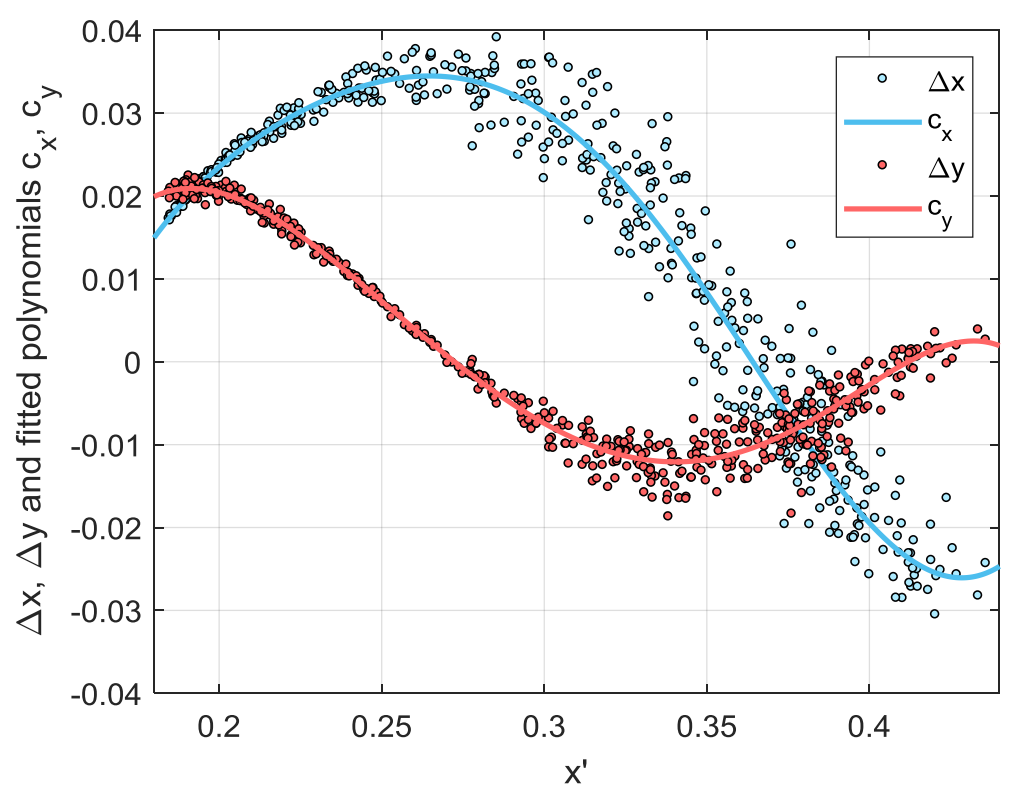

195

Fig. 3 Discretization errors $\Delta x$ and $\Delta y$ in the computation of the $(x, y)$ coordinates as a function of $x^{\prime}$ for the IOCCG synthetized dataset, and corresponding fitted curves $c_{x}$ and $c_{y}$ (Table 1 ).

Their approach provided unbiased hue and FU estimates, but left $(x, y)$ biased. Since we consider ( $x, y)$ and also the saturation (s) important for our study, we decided to modify the method and correct biases directly from $(x, y)$. We used the same IOCCG synthetized dataset as van der Woerd and Wernand (2015) and van der Woerd and Wernand (2018) to perform this correction. From every $R_{r s}$ in the dataset, the "exact" $(x, y)$ coordinates were calculated using eqs. (1-2). Then, every $R_{r s}$ was convoluted with the SeaWiFS response functions centered at 412, 443, 490, 510, 555 and $670 \mathrm{~nm}$, and from the spectra at the SeaWiFS bands, the "biased" $\left(x^{\prime}, y^{\prime}\right)$ estimates were calculated using eqs. (4 and 2). Fig. 3 shows the plotted errors $\Delta x=x^{\prime}-x, \Delta y=y^{\prime}-y$ as a function of $x^{\prime}$. Similarly to what reported by van der Woerd and Wernand (2015) and van der Woerd and Wernand (2018) for the hue angle, the errors $\Delta x$ and $\Delta y$ are largely systematic and therefore they can be approximated by fitting functions. Here, we found that $6^{\text {th }}$ grade polynomials provided good fits: $c_{x}=\sum_{i=0}^{N} p_{i} h^{i}, c_{y}=\sum_{i=0}^{N} q_{i} h^{i}$ (coefficients provided in Table 1 ), where $\mathrm{N}=6, \mathrm{~h}$ is the centered and normalized $x^{\prime}$, based on the mean and standard deviation of the training dataset: $h=\left(x^{\prime}-m\right) / s$, with $\mathrm{m}=0.3017$ and $\mathrm{s}=0.07398$. Finally, biases are corrected as $\mathrm{x}_{\mathrm{cor}}=\mathrm{x}^{\prime}-\mathrm{c}_{\mathrm{x}}, \mathrm{y}_{\mathrm{cor}}=\mathrm{y}^{\prime}-c_{\mathrm{y}}$. For the remainder of the article, we refer to the computed quantities $\left(x_{\text {cor }}, y_{c o r}\right)$ as the exact $(x, y)$.

Table 1 Coefficients of the polynomial fits to correct biases in $(x, y)$, times 100.

\begin{tabular}{|l|l|l|l|l|l|l|l|}
\hline $\mathrm{l}$ & 0 & 1 & 2 & 3 & 4 & 5 & 6 \\
\hline $100 \cdot \mathrm{p}_{\mathrm{i}}$ & 2.9653 & -2.0032 & -2.1461 & 0.034326 & 0.40886 & 0.091567 & -0.03510 \\
\hline $100 \cdot \mathrm{q}_{\mathrm{i}}$ & -0.7786 & -1.5604 & 1.2188 & 0.44135 & -0.1067 & -0.024582 & -0.03253 \\
\hline
\end{tabular}

From the original ESA-OC-CCI V2.0 climatological files, associated files were generated, that exported the original latitude, longitude and time variables and incorporated $x, y$, the hue angle and FU.These products have uncertainties though. Assuming an exact source $\mathrm{R}_{\mathrm{rs}}$, the discretization, after systematic biases compensation, leaves residual errors, which are $\Delta x-c_{x}$ and $\Delta y$-cy (Fig. 3). These errors are higher for green waters than for blue waters. This result can be interpreted as follows: the SeaWiFS bands are appropriate for capturing all relevant spectral features of blue waters, but for 
greener waters, some information is lost. Specifically, for $x<0.25$ (blue waters), the following uncertainties, quantified as the standard deviations for $\mathrm{x}, \mathrm{y}$ and $\alpha$ are obtained: $\sigma_{\mathrm{x}}=8.03 \cdot 10^{-4}$, $\sigma_{y}=6.62 \cdot 10^{-4}$ and $\sigma_{\alpha}=0.13^{\circ}$. For $x \geq 0.25$, one obtains $\sigma_{x}=5.14 \cdot 10^{-3}, \sigma_{y}=2.20 \cdot 10^{-3}$ and $\sigma_{\alpha}=2.61^{\circ}$. Even in this last case, uncertainties can be assumed very small compared to other sources of uncertainties in ocean color.

Such uncertainties must be added to the uncertainties of the $R_{r s}$ at sea level when these are uncertainty maps related to $R_{r s}$ at each band, derived from comparison with in-situ observations. In brief, $R_{r s}$ uncertainties were calculated for matchups to an in-situ dataset and discriminated according to Moore's OWTs (Moore et al. 2009). These uncertainties were then extended to the global map by calculating the OWT membership for every pixel and assuming the uncertainty as the weighted average of the uncertainties for all OWTs in the matchups, using the pixel's class memberships as weights. Full details can be found at the Product User Guide (Grant et al. 2015).

ESA-OC-CCl provides maps of systematic biases and RMS differences. Biases were removed from the data and subtracted from the RMS differences in the final uncertainty estimation. Resulting standard deviation maps showed some seasonal variability, that was small compared to the differences between bands. Geographically and seasonally averaged standard deviations for each $\mathrm{R}_{\mathrm{rs}}$ band are $\sigma_{\mathrm{Rrs}}=(0.0012631,0.001063,0.0007631,0.00061579,0.00051381,0.0002132) \mathrm{sr}^{-1}$. These uncertainties were propagated to the $(x, y)$ and $\alpha$ estimations. We derived these variables and their associated uncertainties from the IOCCG dataset but now adding random and normally distributed errors with zero mean and $\sigma_{\mathrm{Rrs}}$ standard deviation to the re-sampled $\mathrm{R}_{\mathrm{rs}}$ at the SeaWiFS bands, always using the coefficients of Table 1 . We repeated the procedure 1000 times and obtained the uncertainties for $x<0.25: \sigma_{x}=0.011, \sigma_{y}=0.024$ and $\sigma_{\alpha}=6.44^{\circ}$. For $x \geq 0.25$, we obtained $\sigma_{x}=0.026$, $\sigma_{y}=0.041$ and $\sigma_{\alpha}=18.38^{\circ}$. Thus, uncertainties in $\mathrm{CCl} \mathrm{R}_{\mathrm{rs}}$ exceed in one or two orders of magnitude uncertainties in the $(\mathrm{x}, \mathrm{y})$ and $\alpha$ estimations from an exact discrete spectrum, but overall the total uncertainties are low enough to obtain reliable estimates using $\mathrm{CCl}$ data, especially over blue waters. There, uncertainties in the hue angle are about $3 \%$ of its value, whereas for green waters, uncertainties are about $20 \%$.

\subsection{Class membership}

Optical water types have been proposed as tools for algorithm comparison and merging (Jackson et al. 2017). In order to avoid discontinuous boundaries between classes, the class memberships have been suggested as weights for class-algorithm blending. Class memberships are also useful for generating mapped product uncertainties. Uncertainties are estimated for every class in a matchup dataset and are extrapolated to a given pixel by calculating the class memberships of it and estimating the uncertainty as the weighted averaged of the calculated uncertainties per class, using the class memberships as weights (Grant et al. 2015). However, the $\mathrm{R}_{\mathrm{rs}}$ of an OWT dataset are not any orthogonal basis functions and correspondingly, the class membership coefficients of a given $R_{r s}$ are not any eigenvalues. This approach is therefore heuristic and may generate methodological doubts, but still it may be applicable as a fit-for-purpose mechanism. 

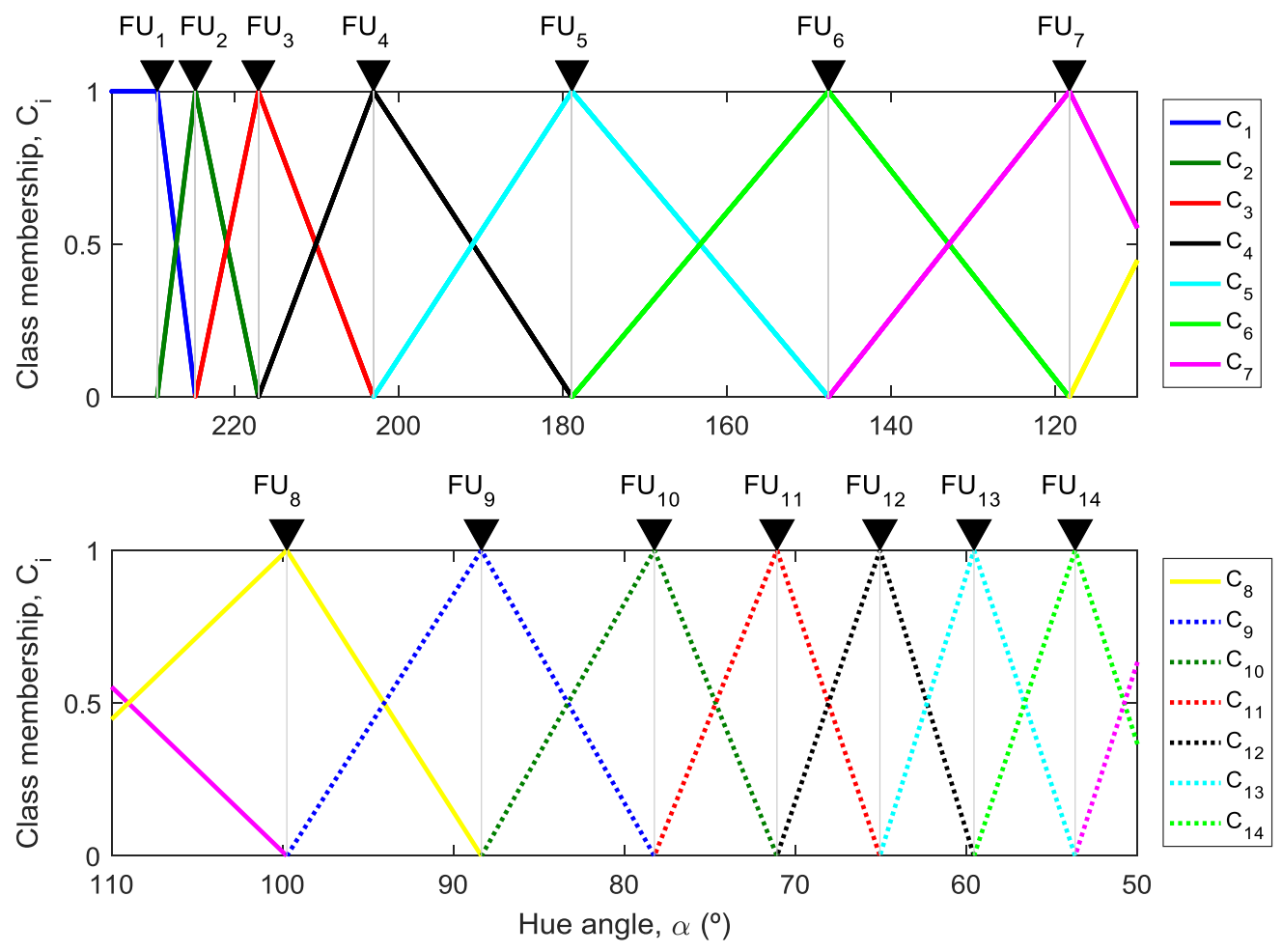

Fig. 4 Class membership functions as function of the hue angle.

Unitarity is a desired property of any set of class membership coefficients. Additionally, for the sake of an easier interpretation, coefficients shall be zero for classes that are far enough from a given spectrum, and shall have non-zero values for a reduced number of classes. Here, we propose a class membership coefficient set such that, given a $R_{r s}$, its membership is non-zero only for the upper and lower FU classes, being their values $C_{U}$ and $C_{L}$, respectively, both memberships adding up to one and being proportional to the distance in hue angle units. More specifically, for a given $R_{r s}$, the hue angle is calculated, $\alpha_{R}$. If $\alpha_{L}$ and $\alpha_{U}$ are the hue angles of the nearest lower and upper FU class, respectively, then the membership value for each is, respectively: $C_{U}=\left(\alpha_{R}-\alpha_{L}\right) /\left(\alpha_{U}-\alpha_{L}\right), C_{L}=\left(\alpha_{U}-\right.$ $\left.\alpha_{R}\right) /\left(\alpha_{U}-\alpha_{L}\right)$. If $\alpha_{R}$ is lower than the hue angle of $\mathrm{FU}_{1}$ (or higher than $\mathrm{FU}_{21}$ ), then a membership equal to one is assigned to the nearest and zero to the rest. The graphical result of these definitions is shown in Fig. 4. By definition, these classes do not carry information on spectral similarity. Every spectrum always has a total membership equal to one, no matter how the spectral shape differs from those of the FU. However, a real spectrum is never going to have a random shape. We show later in the article that the optical variability in the world's surface waters is limited and is well described by the hue angle to a first order.

\section{Results and discussion}

\subsection{Color distribution of global reflectances}

The dimensionality reduction from $(x, y)$ to the hue angle as a color descriptor implies some loss of information unless the interdependency between $x$ and $y$ is very strong, i.e., case 1 . Fig. 5 plots the $(x, y)$ (panel a1)) and the $(\alpha, s)$ polar coordinates (panel b1)) of the ESA-OC-CCl v2.0 global climatological monthly $R_{r s}$. The frequency distributions of the $(x, y)$ coordinates are shown in panels a2) and a3), whereas the respective for $(\alpha, s)$ are shown at panels b2) and b3). 

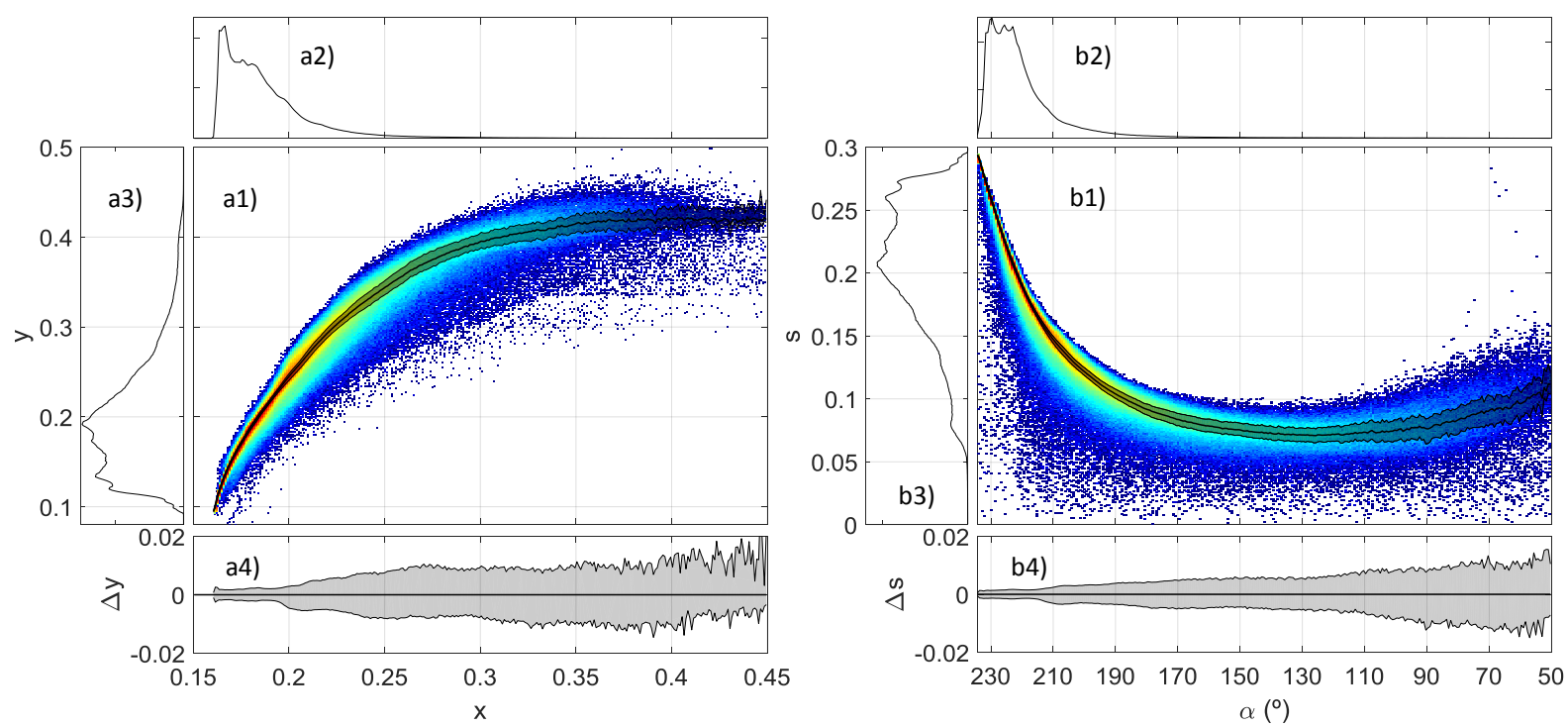

Fig. 5 Distributions of the global climatological ESA-OC-CCl v2.0 $R_{r s}$ on the $(x, y)$ plane and in polar coordinates $(\alpha, s)$. Panel a1) log-density plot of $(x, y)$ distribution, with dot color indicating increasing data density. The moving median of $y$ for every $x$ as thick line, and the $25^{\text {th }}$ and $75^{\text {th }}$ percentiles as band boundaries, are plotted on top. a2) distribution of $x$. a3) distribution of $y$. a4) same band as panel a1) but setting the moving median of $y$ as ordinates origin. Panels b1) to b4) are equivalent to a1) to a4) but replacing $x$ by $s$ and $y$ by $\alpha$.

Fig. 5 shows that all global variability occupies a very limited area in the $(x, y)$ and $(\alpha, s)$ planes, distributing along a trail from deep blue until green-brown color. More importantly, this trail is very narrow and, to a first order, it is distributed along a line (thick lines in panels a1) and b1)), evidencing a strong inter-dependency. Therefore, for a given $\alpha$, an average $s$ can be predicted. This statement is especially true for the bluest waters (panels a4) and b4)), confirming the hypothesis that a single parameter condenses well all optical information. On the other hand, the trail progressively spreads with increasing $\mathrm{x}$ or decreasing $\alpha$, illustrating an increasing optical complexity. At some point, for green-brown waters, a given hue angle can be associated to a wider range of saturations (and spectral shapes) with correspondingly different constituent concentrations, as happens in case 2 waters. These results show that there is not a clear threshold for the separation between case 1 and case 2 waters, although the band thickness $\Delta$ s appears to remain relatively stable from the blue waters until $\alpha \approx 214^{\circ}$, staying $\Delta s<2 \cdot 10^{-3}$ and then sharply increasing. This boundary falls in the class $\mathrm{FU}=3$ (blue waters) and could be defined as separator between case 1 and case 2 waters. Around 80 $\%$ of the world's surface waters fall under this case 1 classification (see frequency distribution of the hue angle in panel b2)), including all oceans and big seas. Description of annual variability of selected marine areas is provided further on.

\subsection{Class memberships based on the hue angle}

Seasonal variation of the class memberships 2 and 4 (C2 and C4) is shown in Fig. 6 for the Mediterranean and Black Seas, using also the ESA-OC-CCI v2.0 global climatological monthly $\mathrm{R}_{\mathrm{rs}}$. Class memberships are functions of the hue angle. They have value one when the hue angle of a pixel is equal to that of the FU classes 2 and 4, respectively, and fall linearly to zero when the hue angle is that of the adjacent FU classes (Fig. 4). Classes are defined such as a pixel has non-zero membership for a maximum of two adjacent classes, so pixels showing non-zero values for $\mathrm{C} 2$ and $\mathrm{C} 4$ are disjoint sets and can be plotted on the same map. 

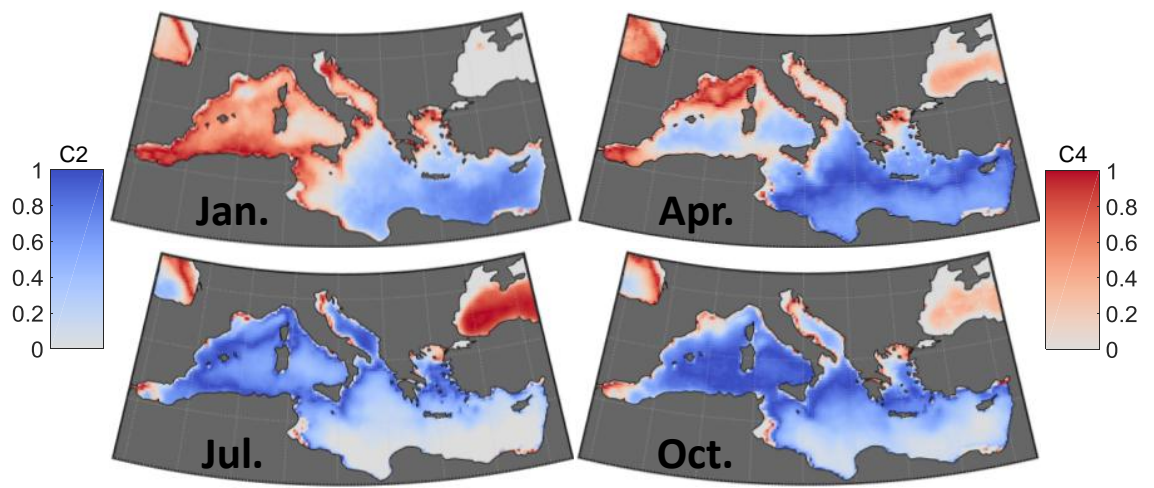

Fig. 6 Color maps of membership to class 2 and class 4 of the Mediterranean Sea for the climatological months of January, April, July and October, based on the ESA-OC-CCl v2.0 global climatological monthly $R_{r s}$.

The map of January clearly distinguishes between the eastern and the western Mediterranean: the eastern Mediterranean has medium C2 membership, increasing towards the more oligotrophic areas, whereas the western displays $\mathrm{C} 4$ membership and has higher values towards the coastal areas. The Black Sea has zero values for $\mathrm{C} 2$ and $\mathrm{C} 4$, indicating a dominance of higher classes. From spring to summer, water becomes bluer in both basins, as indicated by higher $\mathrm{C} 2$ values for the eastern and western Mediterranean, with the exceptions of the Alboran Sea and the bloom at the gulf of Lion. The Black Sea shows increased C4 membership. In July, eastern Mediterranean waters are very blue which leads to reduced $C 2$ membership, and more dominance by $C 1$, while the western have higher values and almost no presence of C4 membership. The Black Sea displays the highest C4 membership values, except the northern coastal areas, whose waters are greener. In October, water is tending back towards greener colors, which translates in higher C2 memberships in the western Mediterranean, while the Black Sea starts to reduce the C4 membership and tends to higher classes.

\subsection{Global maps of seasonal Forel-Ule variability}

Application of the FU algorithm to the ESA-OC-CCl v2.0 global climatological monthly $\mathrm{R}_{\mathrm{rs}}$ (Fig. 7) reveals a vast majority of zones falling on the lowest FU classes. $94 \%$ of the surface waters belong to FU between 1 and 4 and 99\% belong to the first 10 classes. The ultra-oligotrophic zones are permanently classified in $\mathrm{FU}=1$, although their extension does have seasonal variability. $\mathrm{FU}=2$ zones have an overall higher surface area. Equatorial, coastal and middle to high latitude seas occupy higher FU values. All oceanic zones are restricted to FU from 1 to 4.
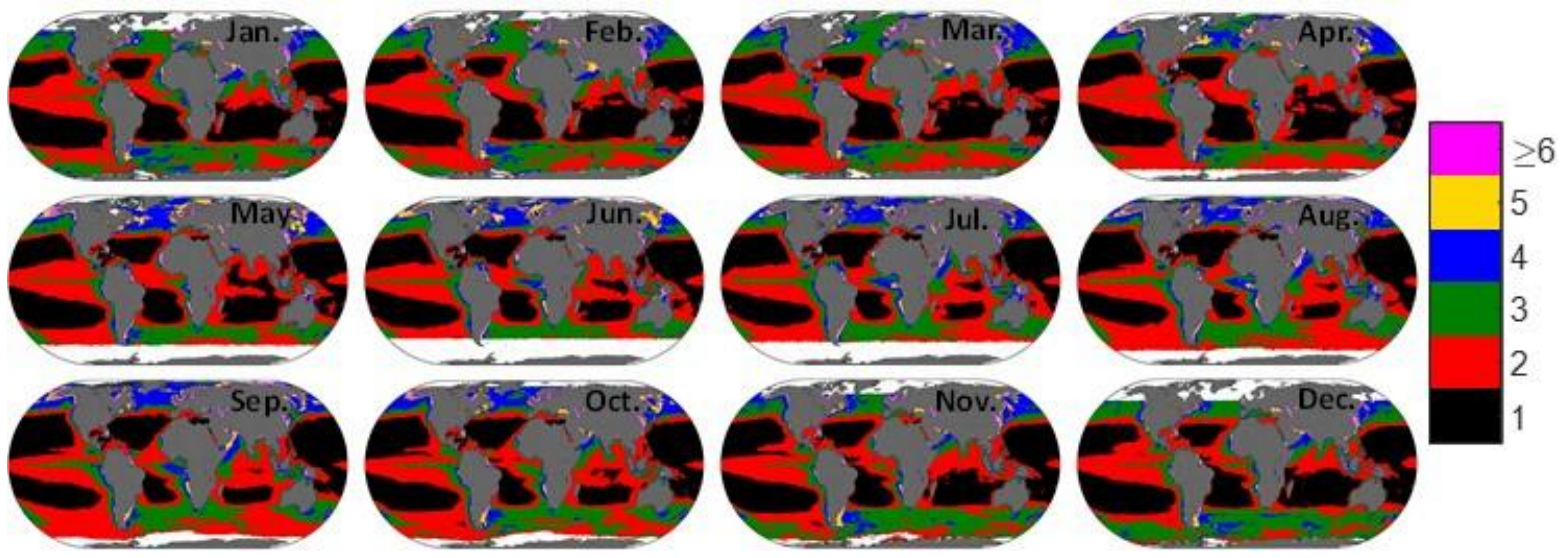

Fig. 7 Global FU monthly variability based on the ESA-OC-CCI v2.0 global climatological monthly $R_{r s}$.

\subsection{Forel-Ule optical water types}


The FU OWTs (Fig. 8) are constructed by clustering all $\mathrm{R}_{\mathrm{rs}}$ belonging to a particular FU index. By using the climatological satellite data to build the OWTs, a good representation of average marine reflectances is ensured.
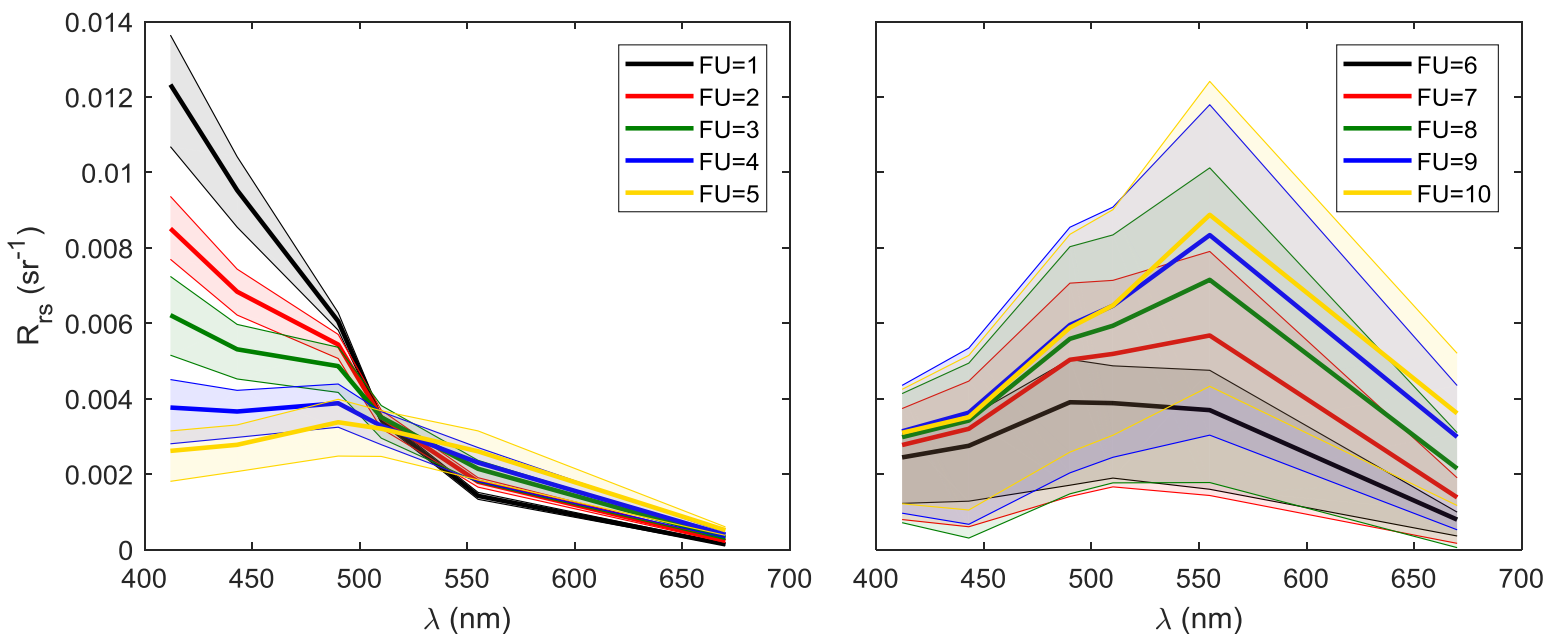

344

Fig. 8 Remote-sensing reflectances corresponding to the first $10 \mathrm{FU}$ water types, obtained from the ESA-OC-CCl v2.0 global climatological monthly $R_{r s}$. Bold traces correspond to median values and bands extend between the $25^{\text {th }}$ and $75^{\text {th }}$ percentiles. Data of all classes can be found at Table A1.

The FU OWTs nicely represent many different water types: the first numbers are typical of clear oceanic waters, displaying decreasing $R_{r s}$ values at blue wavelengths and increasing at the green with increasing FU. As FU increases beyond $5, R_{r s}$ are more characteristic of green coastal waters and include higher ranges of concentrations and shapes.

Given that FU estimations can be made visually or with simple instruments like photographic cameras (Busch et al. 2016), and also given the existence of long-term FU records, it is of value to provide indicators of optical descriptors that are common in optical oceanography, like diffuse attenuation coefficient $\left(K_{d}\right)$, Secchi disk depth $\left(\mathrm{z}_{\mathrm{SD}}\right)$, and chlorophyll concentration $\left(\mathrm{C}_{\mathrm{a}}\right)$.

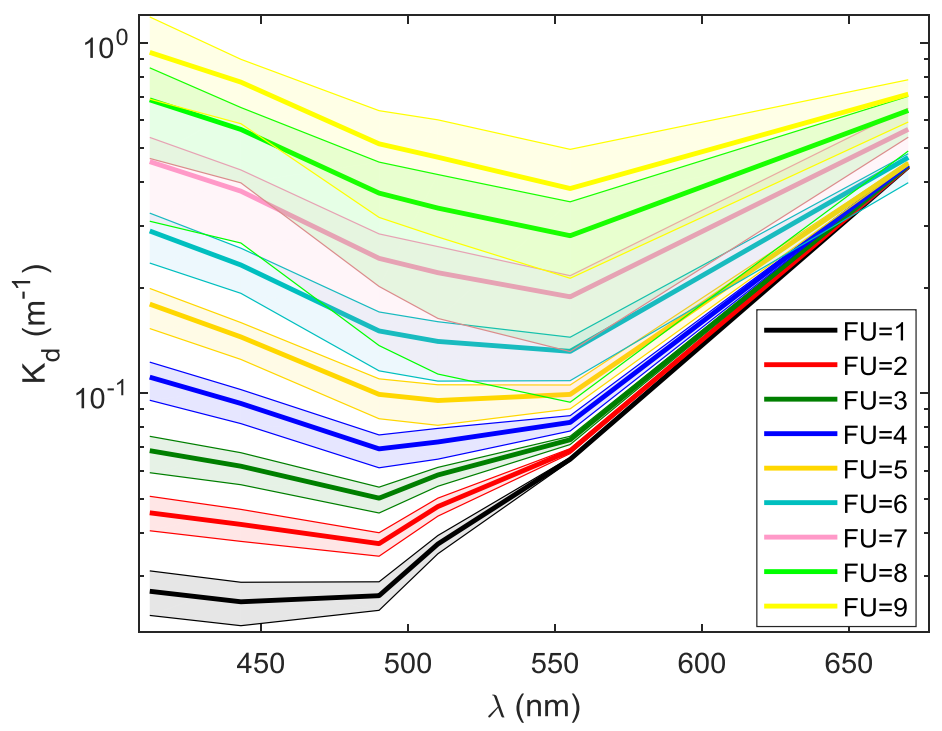

Fig. 9 Diffuse attenuation coefficient of downwelling irradiance of the first 9 FU classes, representing the median in bold line and the interval between the $25^{\text {th }}$ and $75^{\text {th }}$ percentiles in shaded band. For a complete description, the reader is referred to Table A2. 
The FU-related $K_{d}$ classes are calculated by deriving $K_{d}$ on a pixel basis (Lee et al. 2002; Lee et al. 2013) and clustering them based on FU. They are shown in Fig. 9 . $K_{d}$ increases monotonically at every band as FU increases, with a red shift of the window of maximum light penetration, relevant for $\mathrm{z}_{\mathrm{SD}}$ calculations (Lee et al. 2015). $\mathrm{FU}=1$ has the minimum at $443 \mathrm{~nm}, \mathrm{FU}=2$ to 4 have the minimum at $490 \mathrm{~nm}, \mathrm{FU}=5$ has the minimum at $510 \mathrm{~nm}$, and $\mathrm{FU}=6$ to 10 have the minimum at $555 \mathrm{~nm}$.

Light extinction in the ocean is an important parameter for heat budget calculations and ecosystem modeling, and can be linked to underwater visibility. Modelers who need to assume a light extinction model can take advantage of this classification by downloading these climatological FU maps and adjusting light extinction models to their specific zone and season. If models already predict light extinction, cross-checking with this climatology can provide indication about the accuracy of the modeling.
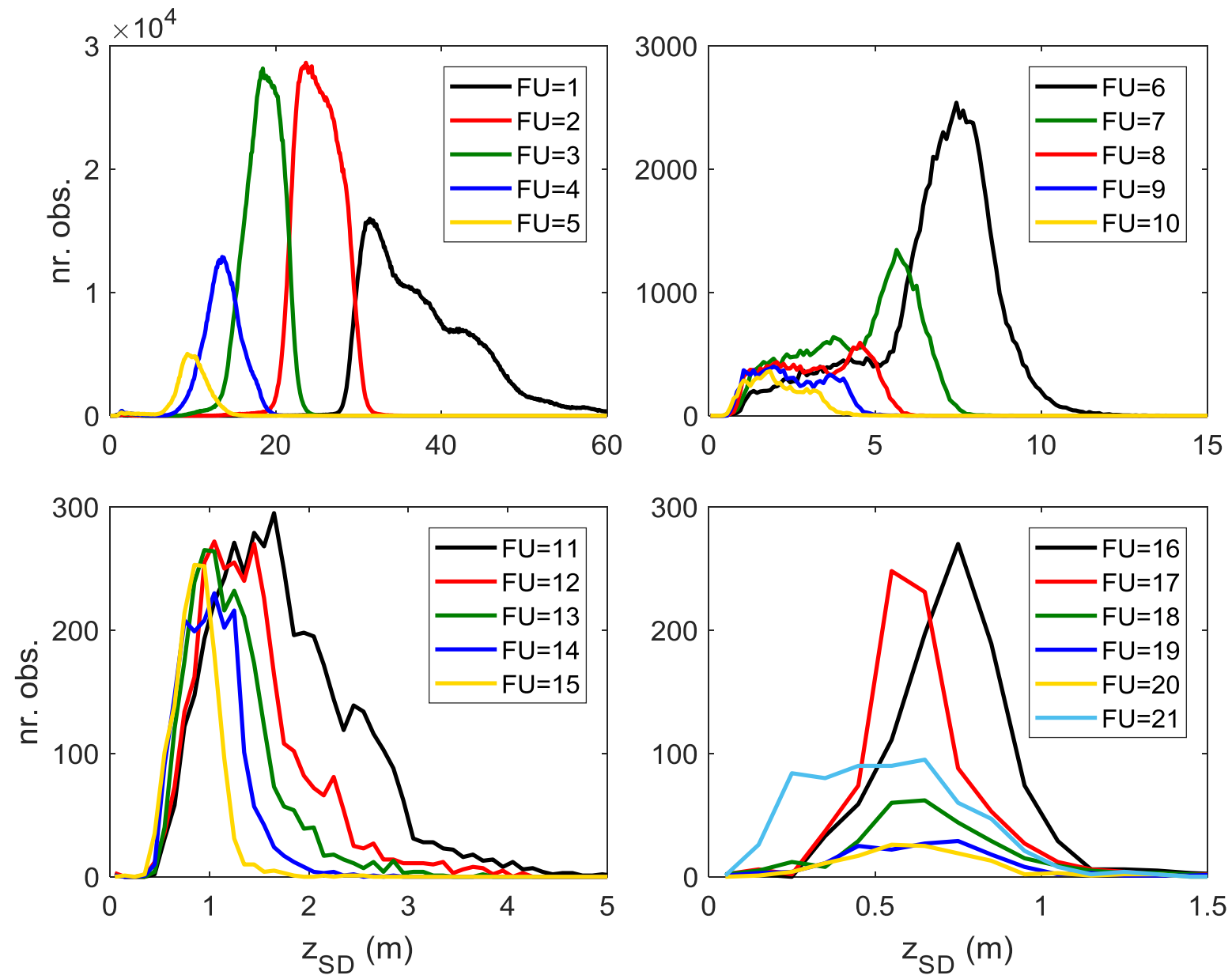

Fig. 10 Secchi disk depth histograms for each FU class. Each histogram aggregates all $z_{S D}$ derivations (Lee et al. 2015) from the ESA-OC-CCl v2.0 global climatological monthly $R_{r s}$ whose per-pixel associated FU have the same value. Statistical descriptors can be found in Table A3.

Secchi disk depth generally decreases as FU increases. The class FU=1 has a $\mathrm{Z}_{\mathrm{SD}}$ distribution with a very wide and asymmetric shape due to its dead-end position, until $z_{S D}=60 \mathrm{~m}$. Its shape suggests that it may be composed of a multipolar distribution, which may be related to separate oceans. This case exemplifies well that $F U=1$ is very ambiguous for representing an average oligotrophic ocean. The next low FU distributions are bell-shaped for oceanic waters, but as FU reaches 6 , a second population appears at the left of the bell shape: these observations are linked to coastal zones with different optical properties, where sediments and CDOM reduce transparency. 

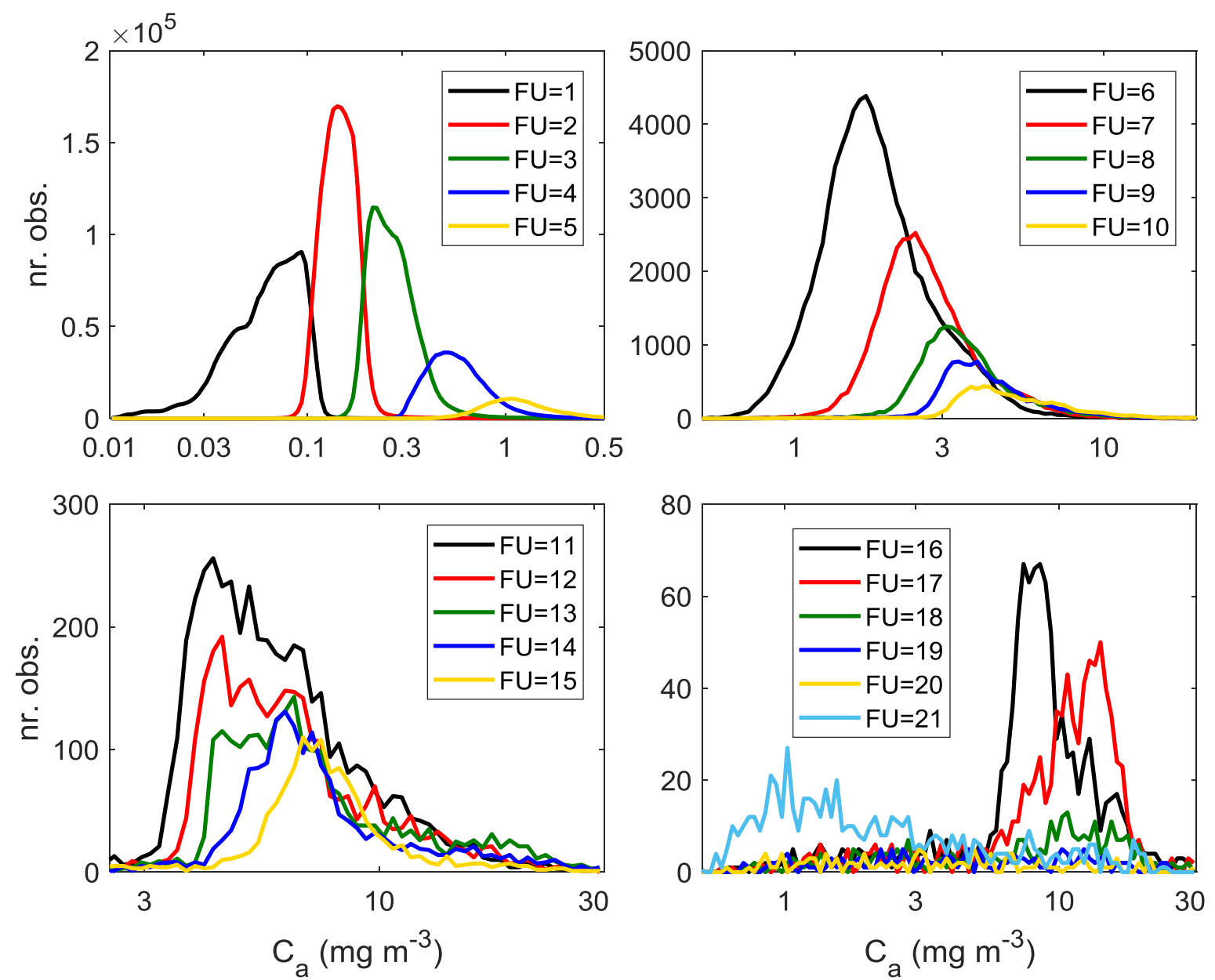

Fig. 11 Chlorophyll concentration histograms for each FU class. Each histogram aggregates all $\mathrm{C}_{\mathrm{a}}$ data the ESA-OC-CCl v2.0 global climatological monthly $C_{a}$ dataset whose per-pixel associated FU have the same value. Statistical descriptors can be found in Table A4.

The histograms of chlorophyll concentration for every FU class (Fig. 11) reveal a similar but inverted shape than $z_{\mathrm{SD}}$ for oceanic waters, as expected, though having a general Gaussian shape, even for optically-complex waters, perhaps suggesting that the left tails of the $\mathrm{z}_{\mathrm{SD}}$ distributions for FU 8 to 10 were caused by sediments and CDOM. 

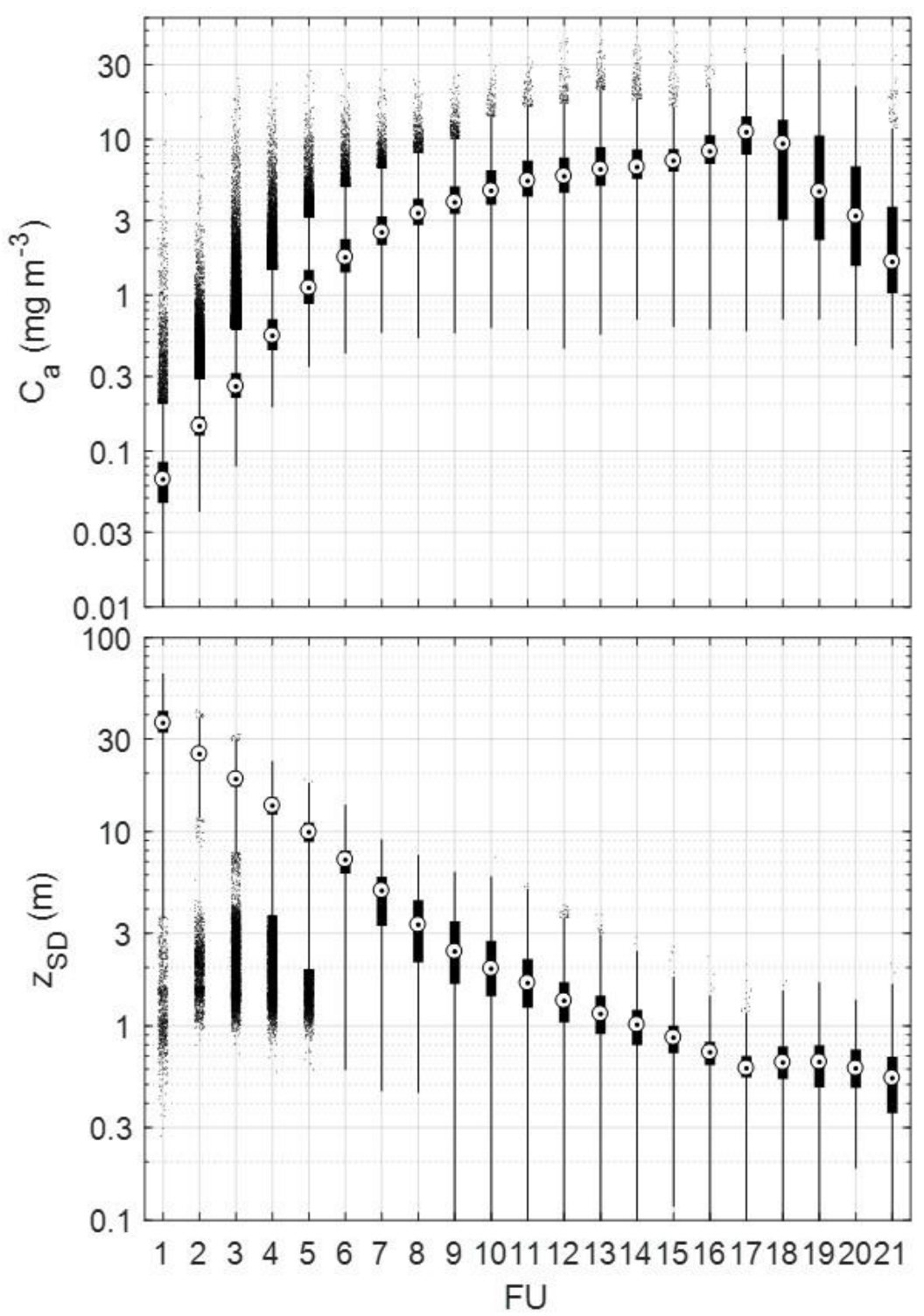

FU

Fig. 12 Chlorophyll concentration and Secchi disk depth box plots for each FU optical water type. The median is plotted as a dot inside a white circle. The interquartile range is delimited by the box around the median. Whiskers extend until three times the interquartile range below and above the first and third quartile, respectively. Data beyond the whiskers range are considered outliers and are plotted as dots. Statistical descriptors can be found in Tables A3-A4.

Box plots of chlorophyll concentration and Secchi disk depth for every FU condense well the information in the former histograms. The progression is the expected for the blue-green range, with $\mathrm{C}_{\mathrm{a}}$ increasing and $\mathrm{z}_{\mathrm{SD}}$ decreasing until $\mathrm{FU}=17$. From this point on, $\mathrm{C}_{\mathrm{a}}$ starts a sharp decrease. Here, very high CDOM concentrations are expected to decrease light availability for the primary producers and thus limiting $\mathrm{C}_{\mathrm{a}} . \mathrm{z}_{\mathrm{SD}}$ does not show significant variations at the highest FU classes.

\subsection{Seasonal variability of selected marine areas}

Fig. 13 shows a map of series-averaged $C_{a}$. This map highlights the five ultra-oligotrophic gyres. These are characterized by anticyclonic circulation, downwelling and thick thermoclines. Depressed nutricline levels limit the algal development and subsequent biogeochemical processes. While their biological activity is small compared to other areas, their vast size makes their contribution to the global productivity and biogeochemistry significant (Morel et al. 2010). Other zones display higher $\mathrm{C}_{\mathrm{a}}$ values. Middle-to-high oceans are subject to nutrient-rich currents. Shelf seas are more sensitive to 
terrestrial runoff and bottom resuspension, and upwelling coastal areas are known for the high phytoplankton biomass. Enclosed and semi-enclosed seas follow their own dynamics (Colella et al. 2016; Kopelevich et al. 2004; Pitarch et al. 2016).

For a more detailed study about color variability across the globe, we defined twenty-one zones (Table 2, Fig. 13) that represent a wide range of optical variability. The most oligotrophic inner cores of the gyres were selected. Other marine zones were also included, from the equatorial pacific to mid-latitude oceanic zones, enclosed seas, shallow seas and coastal zones. For each zone, the median of all valid pixels was calculated. The goal here is to understand how the optical variability in each region is resolved by increasingly simplified optical descriptors, from $(x, y)$ to the hue angle, to FU.

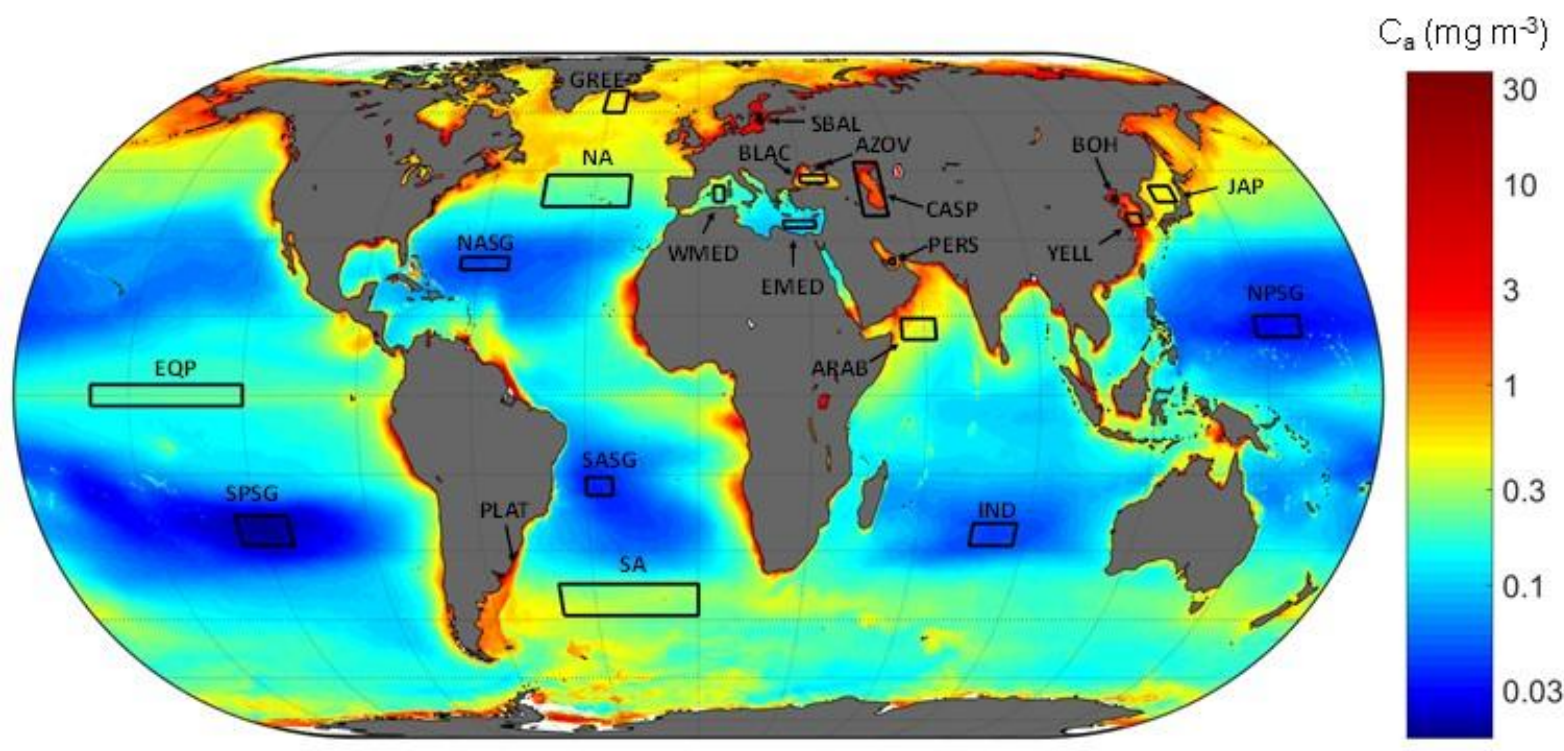

Fig. 13 Selected marine zones for the study of the seasonal color variability, over a map of the seriesaveraged chlorophyll-a concentration.

Table 2 Acronym and bounding coordinates of the study zones (see Fig. 13)

\begin{tabular}{|l|l|l|l|l|l|}
\hline Zone & Acronym & East $\left({ }^{\circ} \mathrm{E}\right)$ & West $\left({ }^{\circ} \mathrm{E}\right)$ & South $\left({ }^{\circ} \mathrm{E}\right)$ & North $\left({ }^{\circ} \mathrm{N}\right)$ \\
\hline North Atlantic subtropical gyre & NASG & -65 & -52 & 24 & 26.5 \\
\hline South Atlantic subtropical gyre & SASG & -30 & -23 & -19 & -15.5 \\
\hline North Pacific subtropical gyre & NPSG & 148 & 160 & 11 & 15 \\
\hline South Pacific subtropical gyre & SPSG & -126 & -112 & -29 & -23 \\
\hline Indian Sea gyre & IND & 75 & 87 & -29 & -24.5 \\
\hline North Atlantic & NA & -45 & -20 & 37 & 44 \\
\hline South Atlantic & SA & -40 & 0 & -44 & -37 \\
\hline Equatorial Pacific & EQP & -160 & -120 & -2 & 2 \\
\hline Off south east Greenland & GREE & -32 & -25 & 60 & 67 \\
\hline Eastern Mediterranean Sea & EMED & 24 & 33 & 32.5 & 34 \\
\hline Western Mediterranean Sea & WMED & 4.5 & 7.5 & 38 & 41.5 \\
\hline Black Sea & BLAC & 42.2 & 44 & 30 & 38 \\
\hline Persian gulf & PERS & 52.4 & 53.8 & 25 & 26.2 \\
\hline Arabian Sea & ARAB & 54 & 63 & 10.5 & 14.5 \\
\hline Caspian Sea & CASP & 47 & 54 & 35 & 47 \\
\hline Yellow Sea & YELL & 121.5 & 125.5 & 33 & 35.5 \\
\hline Southern Baltic Sea & BAL & 19.6 & 20.8 & 57 & 59.5 \\
\hline Azov Sea & AZOV & 36.2 & 37.4 & 45.5 & 46.3 \\
\hline
\end{tabular}




\begin{tabular}{|l|l|l|l|l|l|}
\hline Off Plata river estuary & RPLA & -56.7 & -55.8 & -35.5 & -35.1 \\
\hline Bohai Sea & BOH & 119.8 & 121.2 & 38.2 & 39.2 \\
\hline
\end{tabular}
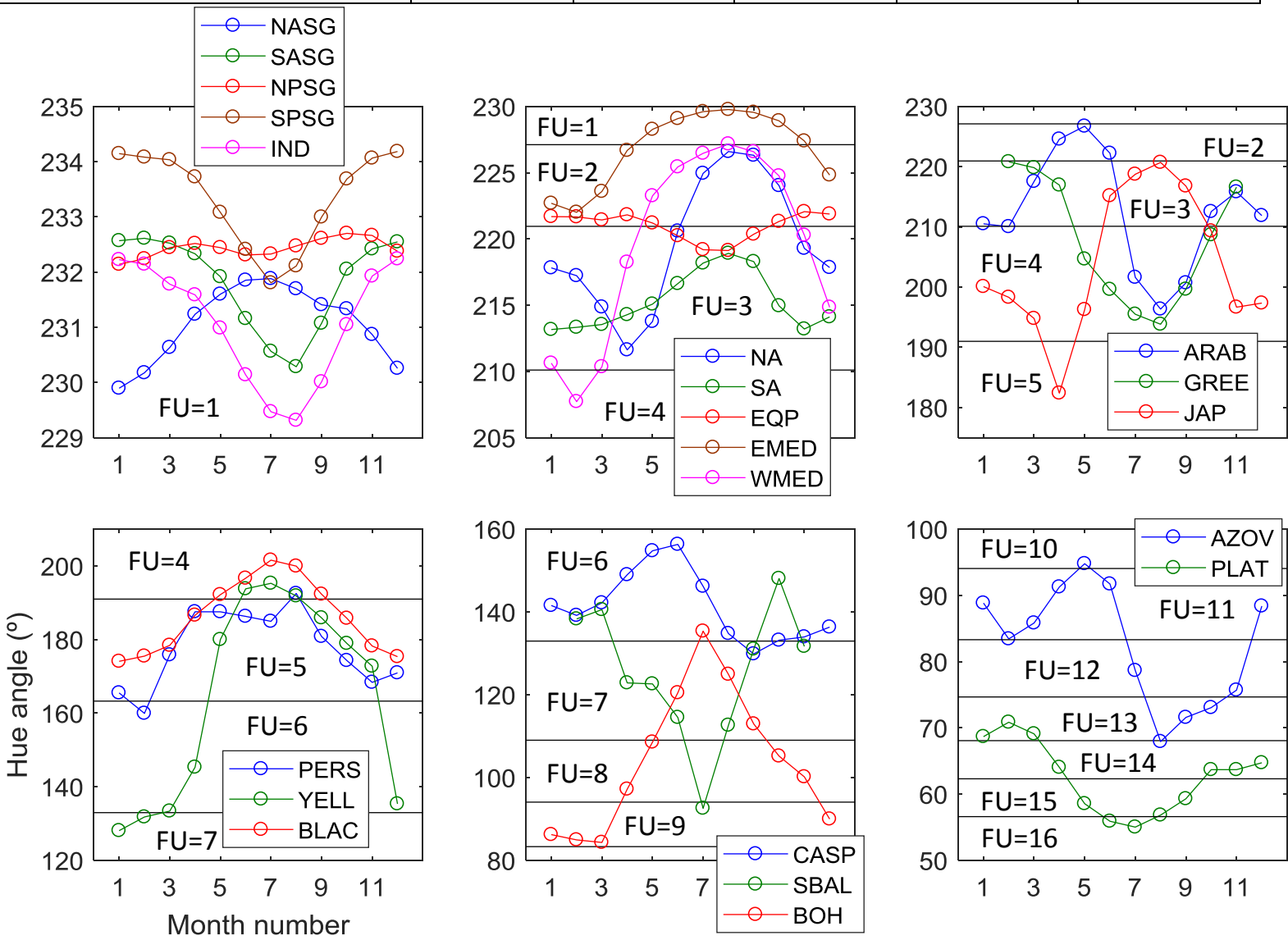

Fig. 14 Hue angle climatological annual variability of selected marine zones (see Fig. 13 and Table 6). The boundaries between consecutive FU classes are also indicated.

Fig. 14 plots the hue angle annual variability of all selected marine zones in Fig. 13 (see Table 2 for boundaries and nomenclature). They all show $\alpha>229^{\circ}$, and are above the boundary between $\mathrm{FU}=1$ and $\mathrm{FU}=2$. Despite being saturated to $\mathrm{FU}=1$, all gyres present a clear hue angle seasonal cycle, with a minimum (greenest) in winter and a maximum (bluest) in summer. Lower winter hues are related to vertical mixing that allows some underlying waters, richer in nutrients, to reach lower depths. Higher hues are associated with a decline in phytoplankton, which is limited by lack of nutrients due to a strong pycnocline formation that stabilizes the water column, limiting the vertical mixing, and thus, nutrient supply to the surface. In the NPSG, nutrient supply during winter mixing seems to be hampered, so that seasonality is smooth. NA and SA, as well as both Mediterranean basins show the same trend, with maxima in winter and minima in summer, though with different dynamic ranges and lower hues, caused by a higher nutrient availability. NA and WMED have the widest variability and SA and EMED the lowest, all crossing between FU 1-3. Somewhat expected, the EQP has very little seasonal variability, crossing the border between $\mathrm{FU}=2$ and 3 across the seasons. Here, nutrients are horizontally advected to this region (Dave and Lozier 2015), causing higher biomass and greener waters. Our data suggests that this process is somewhat higher during the boreal summer, leading to a slight seasonal cycle.

ARAB has the bluest waters in May and the greenest in August, and a secondary blueness peak in November. Phytoplankton blooms in the northwest Arabian Sea during August-September. They are driven by the seasonal monsoon, that triggers upward nutrient fluxes to the euphotic zone, forced by the physical processes of coastal upwelling and offshore Ekman pumping (Brock and McClain 1992). 
GREE follows the dynamics of a boreal sea, displaying blue waters with the maximum hue in winter and the minimum in August, during the summer bloom. Production starts in March and increases slowly because of low temperature. The spring bloom occurs in about May. However, over the summer, nutrient limitation may set in and limit production in concert with a rapid decline in insolation. Thus, the phytoplankton in the open Greenland Sea may be controlled by nutrients replacing light as the limiting factor for phytoplankton production during summer (Richardson et al. 2005).

JAP displays a high oscillation with general characteristics of an oligotrophic sea, with higher pigment concentrations in winter than in summer, plus two characteristic blooms, one in spring, that lowers the hue down to $\mathrm{FU}=5$, and a weaker fall bloom. Kim et al. (2000) explained bloom occurrence as the result of the changing balance between the critical depth and the mixed layer depth. The different bloom intensity can be related to different light availability in both seasons.

Despite its shallow bottom, PERS shows FU values consistent with tropical and subtropical seas. The highest $C_{a}$ in the open-water region of the Gulf take place in winter, while lower concentrations were observed in both spring and summer. A sharp bluing of the water in April is caused by low $C_{a}$ in April, driven by nutrient depletion (Al-Naimi et al. 2017).

YELL displays a huge range of variability, from $\mathrm{FU}=4$ in winter till $\mathrm{FU}=7$ in summer. Sediment resuspension caused by seasonal currents plays a role (Yamaguchi et al. 2012) but the area is also affected by strong summer blooms due to high (and increasing) nutrient discharge (He et al. 2013). Similar dynamics are present in $\mathrm{BOH}$ displays, but accentuated due to a lower distance to land and much shallower waters.

BLAC is a semi-enclosed sea, affected by terrestrial influence, which leads to significant particle backscattering even in open areas (Kopelevich et al. 2004). Its color dynamics is that of a temperate sea, and is driven by Ekman pumping (Kubryakov et al. 2016), with greener hues in winter around $175^{\circ}$, corresponding to $\mathrm{FU}=5$, and bluer in summer, around $200^{\circ}$, corresponding to $\mathrm{FU}=4$.

CASP shows on average the highest hues in June and the lowest in September, consistent with previous results using three years of SeaWiFS data (Kopelevich et al. 2004), although the lack of insitu data in their study could not confirm if the seasonal low hue was caused by $C_{a}$ or other constituents.

SBAL displays seasonal dynamics influenced by an intense summer bloom (Pitarch et al. 2016) that leads to a green-brown color ( $F U=8-9)$. The rest of the year, color is dominated by high amounts of CDOM. Note here the absence of data during the darkest winter months due to low sun zenith angles.

Finally, two edge examples have been found at AZOV and PLAT, known for the high turbidity of their waters. While AZOV shows the highest hues in May and the lowest in August, PLAT shows the highest FU in July and lowest in February. In both cases, seasonality is likely to be a mixture of riverborne sediments and phytoplankton phenology. Dogliotti et al. (2016) documented a seasonal cycle of turbidity at the southern end of the estuary of PLAT that followed the same trends as shown here.

The latter analysis showed the ability of the hue angle to monitor ecosystem variability in a wide range of marine waters. The hue angle compresses all $R_{r s}$ information into a single color indicator, which is theoretically enough in case 1 waters. When sediments and dissolved organic matter vary independently to $C_{a}$, the spectrum can show a wider variety of shapes. As already commented in the methods section, the hue angle does not carry information on the saturation. High saturation can happen in zones with high sediment concentrations where spectrum shows a broader shape, or high CDOM zones, where the magnitude of the full spectrum is low. Saturation can therefore be a second indicator describing optically complex waters. 


\subsection{Optical water types comparison}

494

495

496

497

498

499

500

501

502

\section{3}

504

505

506

507

508

509

510

511

512

513

514

515

516

517

518

519

520

Projecting global $R_{r s}$ and various OWTs on the CIE $(x, y)$ space provides a good graphical assessment of how the latter are representative of the former. There is however, not a clear criterion to judge the goodness of any OWT set applied over a given dataset. So far, their definition and their number has remained arbitrary. Generally, if the purpose is to describe ecosystem variability, the OWTs must cover all the observed variability and have a fine enough resolution across the dynamic range. If the purpose is algorithm delimitation, the number of classes can be tailored to the number of applicable algorithms. Although there is an increasing number of OWTs sets for marine and inland waters, or for specific regions, we restrict our study to those OWTs published for global marine waters, in particular for M15, W16 and J17.
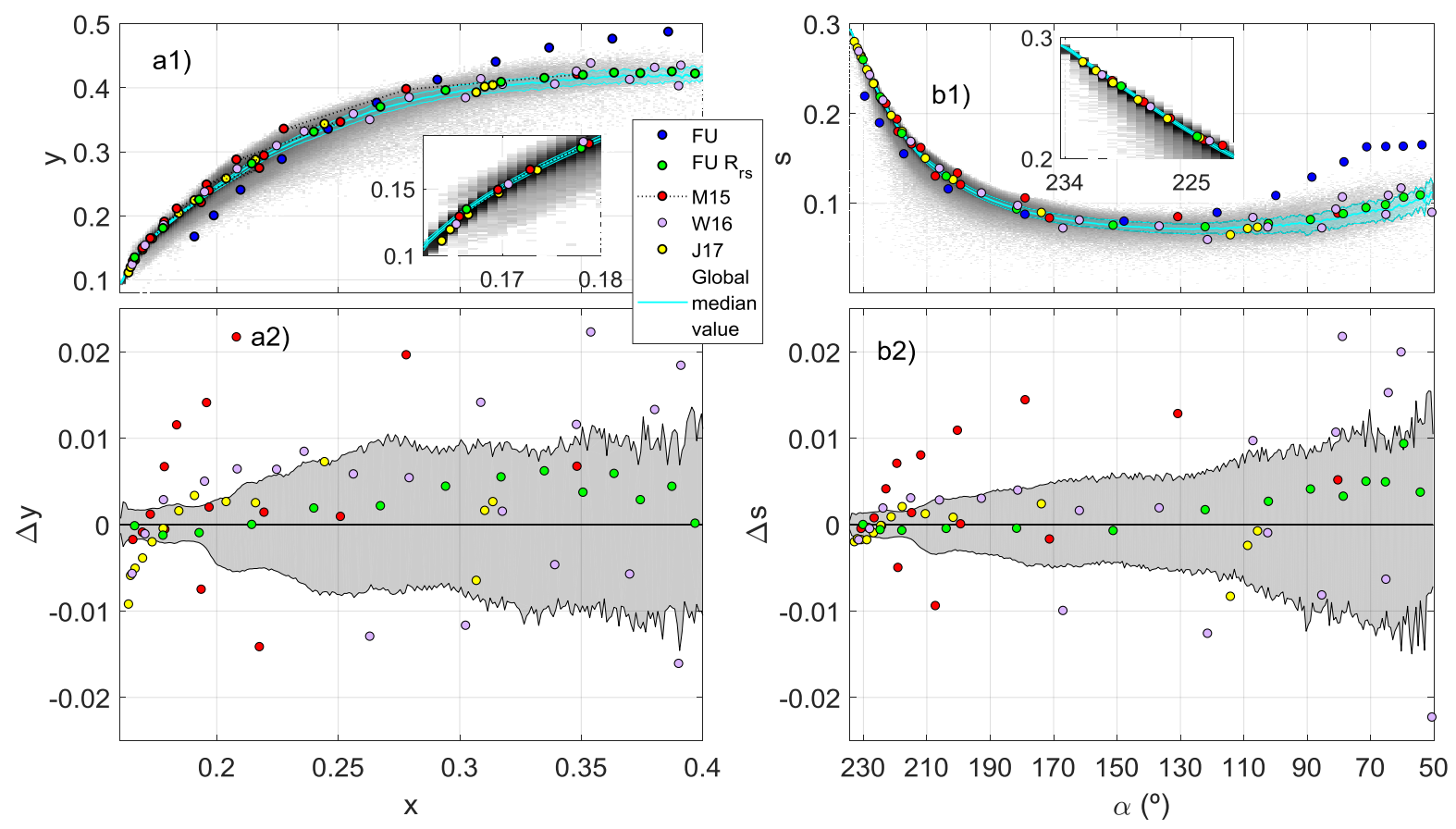

Fig. 15 Top panels show various OWTs projected in the $(x, y)$ plane (panel a1)) and in polar coordinates (panel b1)). The log-density plot of the coordinates derived from global climatological ESA-OC-CCl v2.0 $R_{r s}$ is shown, with the running median and the intervals determined by the $25^{\text {th }}$ and $75^{\text {th }}$ percentiles. Bottom panels represent the differences with respect to the running median.

All OWTs (Fig. 15) fall approximately onto the trail formed by the global $\mathrm{R}_{\mathrm{rs}}$ across all the range except the original FU scale (blue). This scale was designed to visually match the hue of perceived color above water, but whose spectra do not have to match the shape of $\mathrm{R}_{\mathrm{rs}}$. Instead, the coordinates of the FU-derived $R_{r s}$ classes (green) fall very precisely on the trail formed by the marine waters, because they were derived after clustering the same $R_{r s}$ forming the data cloud, being the original FU classes only used as discriminators based on the hue angle. The FU $R_{r s}$ classes cover very evenly the dynamic range although fall short in reaching the bluest waters (see insets in Fig. 15a1,b1). FU=1 is located between the third and the fourth $\mathrm{J} 17$ classes.

The M15 classes were derived from global imagery over coastal waters, although their definition of coastal waters was not based on optics and included very blue waters. Therefore, their clearest class has the color of the bluest Indian Ocean waters and even of the North Atlantic subtropical gyre. At the other extreme, their highest in terms of hue angle is near FU=11, like the turbid coastal waters of the Azov Sea. 
The W16 classes cover a wide dynamic range. The bluest class has the color of the gyres, except the pacific, and the brownest has a hue angle of $39^{\circ}$, which represent a class close to $\mathrm{FU}=16$. This appears then suitable not only for clear marine waters, but also for very turbid and yellow coastal and inland waters.

The J17 OWTs cover the optical variability of the oligotrophic oceans better than the other representing the bluest waters that were missing in the original OWTs (Moore et al. 2001). At the most turbid end, Jackson et al. (2017) noticed that they had fell short in describing turbid waters, since their contribution in their dataset was overwhelmed by that from the clearest ones. For this reason, they decided to add three more spectra, consisting of sediment-laden waters of increasing concentrations. These new classes have very similar hue angle and in the $(x, y)$, they fall nearly on the top of each other. This can be explained by the fact that same sediment type was the same, only varying in concentration. In terms of the science of colorimetry, the last three J17 classes differ in brightness but not in color.

The bluest W16 class and the three bluest J17 waters differ from the oceanic $R_{r s}$ (see lower panels of Fig. 15). These classes have significantly lower saturation (broader spectra) than the $R_{r s}$ they should be representing. This result is unexpected for $\mathrm{J} 17$, as $\mathrm{J} 17$ OWT were generated from OC-CCI $\mathrm{V} 2.0 \mathrm{R}_{\mathrm{rs}}$, as the marine data of this article. A possible explanation might be related to the training data extraction in that $\mathrm{J} 17$, coming from four daily product file per year of the $\mathrm{OC}-\mathrm{CCl}$ series, one in the middle of each season, and geographically sampled from a series of two-by-two degree squares, distributed across the Longhurst provinces.

Higher M15 and W16 classes follow pathways with a sort of zig-zag patterns starting from the green waters, unlike FU and J17, that appear to follow a line along the trail formed by all the marine variation. This is due to the fact that M15 and W16 classes were generated from normalized $R_{r s}$, which made their $R_{r s}$ dataset more sensitive to shape differences, that is different color saturations for a given hue. This pattern is even more pronounced for the W16 dataset. This finding is consistent with the fact that W16 used data collected from a number of specific sites and so might be biased toward conditions related to those sites. Interestingly, the zig-zag pattern does not exist for the bluest M15 and W16 classes, that are well confined inside the average marine variability (Fig. 15, panels a2) and (2)), proving that normalized or non-normalized $R_{r s}$ contain the same information in blue waters. For greener waters, there are spectra than can have a similar hue angle but different spectral shapes: see for instance classes 7 and 8 of M15: both have a very similar hue angle (215.1 and 215.6 degrees, respectively), but completely different spectral shapes: class 7 is characteristic of coastal zones with moderate chlorophyll and little sediment, while class 8 can be related to little chlorophyll but higher sediment concentrations. With their classification based on non-normalized $R_{r s}, J 17$ obtain a single class in this region (their number 9) whose spectra looks somewhat in the middle of classes 7 and 8 of M15.

\subsection{Forel-Ule scale expansion in blue waters}

The previous sections have shown how the FU OWTs exceed the dynamic range of marine waters at the green-yellow end, but fall short at the bluest waters. This feature is nevertheless not a shortcoming for algorithm determination. J17 found that the optimal chlorophyll-a algorithm for their first seven classes was $\mathrm{OCl}$ (Hu et al. 2012). However, if the purpose is to monitor variability, then additional resolution can be added, by the addition of a new bluest class, "FU,". Here, we provide a demonstrative example of this addition. First step is to assign a hue angle to this new class. Based on Fig. 14, we choose the boundary between the classes $\mathrm{FU}_{1}$ and $\mathrm{FU}_{0}$ at $232^{\circ}$, that lays in the middle of the variability within the gyres. Thus, $232^{\circ}$ is the point of equal distance between $\mathrm{FU}_{1}$ and $\mathrm{FU}_{0}$, which leads to $\alpha_{0}=234.55^{\circ}$. Interestingly, this value is above the maximum recorded, which will 
avoid class memberships saturated at the lowest FU. With this choice, even the bluest pixels will have some membership to $\mathrm{FU}_{1}$.

To fully define the color properties, a saturation value must be given. Fig. 16a shows that the original $21 \mathrm{FU}$ classes follow a path in the $(\alpha, s)$ plane. Therefore, we obtain an analytical expression with spline curves and extrapolate this trajectory until $234.55^{\circ}$. This leads to: $s_{0}=0.2621$. Conversion to rectangular coordinates leads to $\left(x_{0}, y_{0}\right)=(0.1813,0.1198)$, shown in Fig. $16 \mathrm{~b}$.
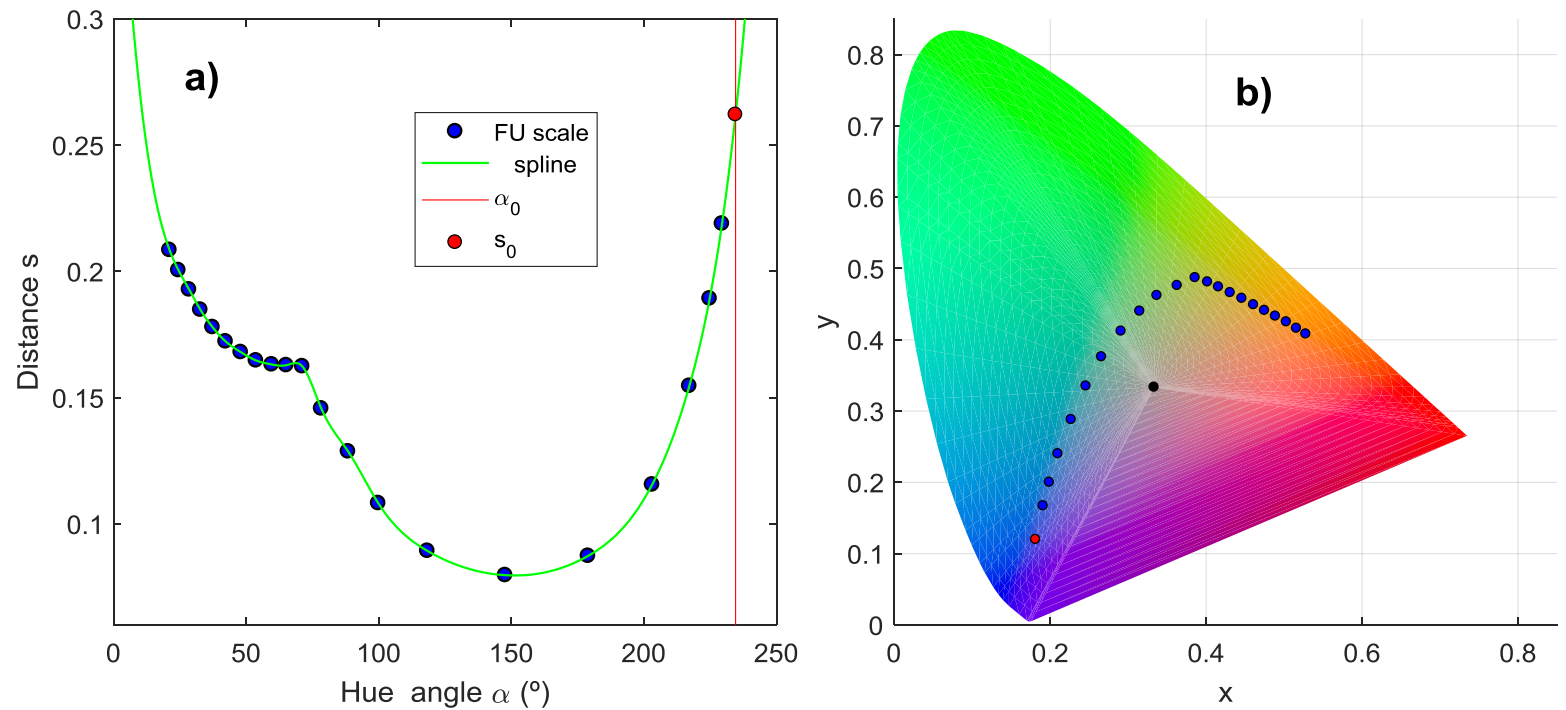

Fig. 16 a) Polar coordinates $(\alpha, s)$ of the 21 original FU classes, after Novoa et al. (2013), with derived spline curve and coordinates $\left(\alpha_{0}, \mathrm{~S}_{0}\right)$ of the new class $\left.\mathrm{FU}_{0} . b\right)$ The CIE 1931 color space in the $(x, y)$ coordinates, with the coordinates of the $21 \mathrm{FU}$ colors (2013) and the new $\mathrm{FU}_{0}$ (red dot).

The new class $\mathrm{FU}_{0}$ has a bluish-purple color and is representative of the clearest oceanic waters. To show enhanced detail in these kind of waters, we have repeated the analysis of Fig. 7, i.e., mapping the global FU variability across a climatological year, but now with the added class, $\mathrm{FU}_{0}$. Now the color variability inside the oligotrophic gyres becomes evident. The gyres are alternating between the classes 0 and 1 . SPSG displays the highest extension of FU=0 in the austral summer, converting almost completely to $\mathrm{FU}=1$ in winter. NPSG displays the second greatest extension of $\mathrm{FU}=0$ areas whereas the NASG is the greenest of all gyres, displaying only small extensions of $\mathrm{FU}=0$ during the boreal summer.
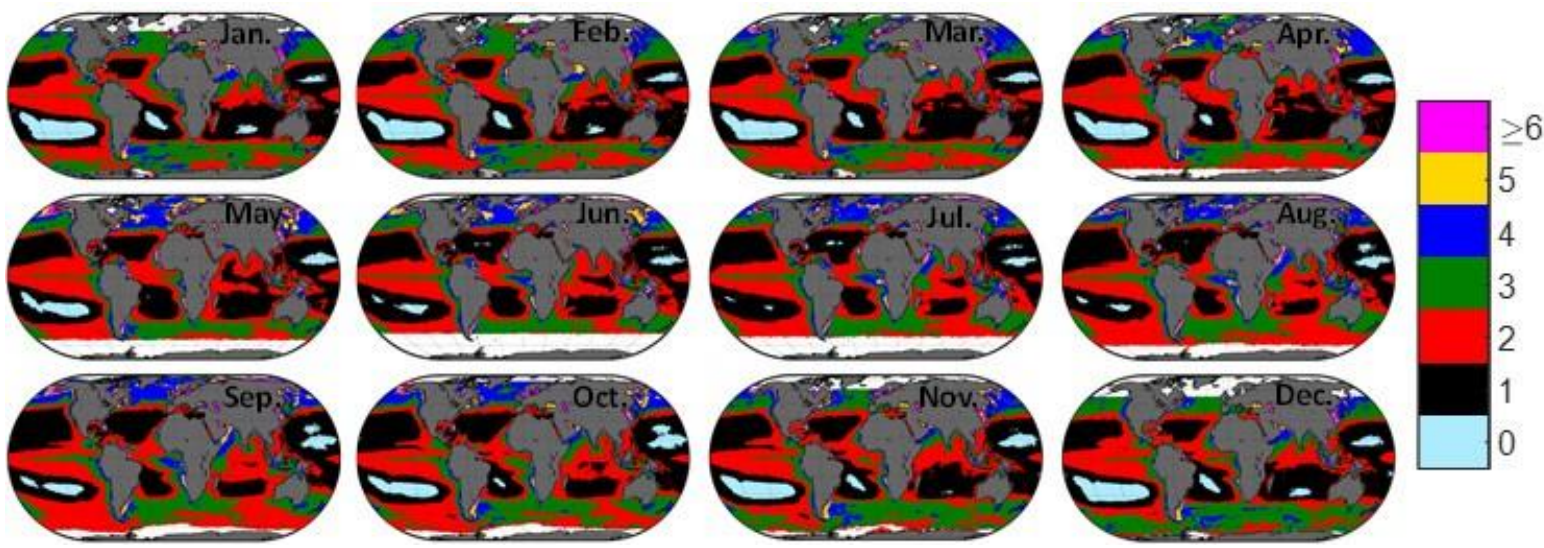

Fig. 17 Global FU-extended annual variability based on the ESA-OC-CCI v2.0 climatological $\mathrm{R}_{\mathrm{rs}}$. 


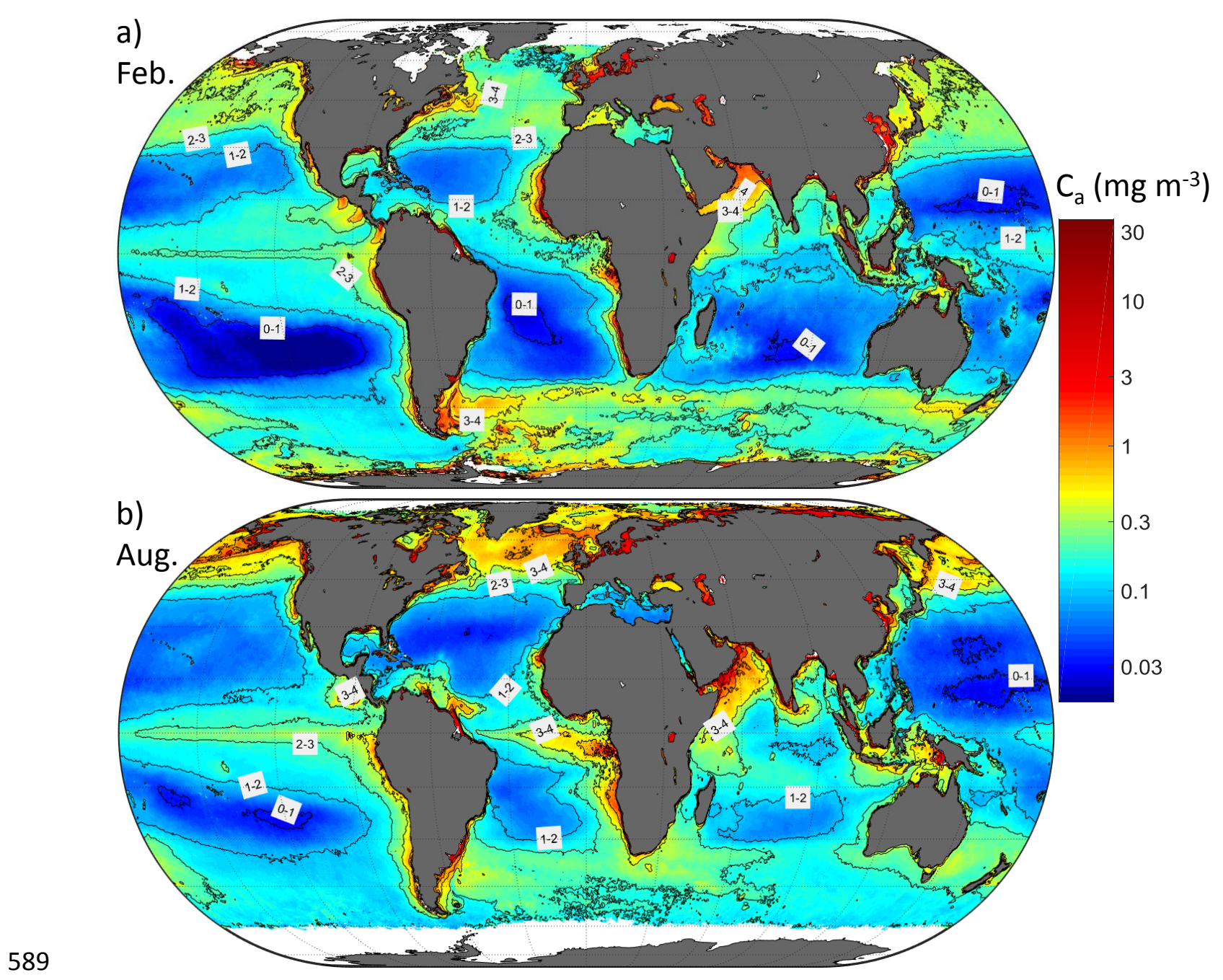

590 Fig. 18 Climatological chlorophyll-a maps for the months a) February and b) August. The contour lines are the boundaries between $\mathrm{FU}$ classes, including the newly developed $\mathrm{FU}_{0}$.

Fig. 18 shows climatological $C_{a}$ maps for the months of February and August. The yearly oscillation is clearly evidenced here: low to mid latitudes display lower $C_{a}$ values in summer and higher in winter while some higher latitudes like the North Atlantic or North Pacific display higher productivity in summer. The boundaries between the corresponding FU classes overlap in both maps and provide clear evidence that $C_{a}$ is driving color at the oceanic scale to a first order. The FU scale is highlighted as an effective delimitator of regions like the oceanic gyres, the equatorial pacific, upwelling zones and oceanic fronts.

The addition of a new lower class can have benefits for tracking the progression of the surface of the most oligotrophic oceanic areas over a given time period. This could be achieved by running the algorithm on the full $\mathrm{CCl}$ series. On the other hand, an altered FU scale would have reduced significance when linking to historic measurements because the new class 0 takes pixels from the old class 1. Consequently, IOPs and AOPs associated to $\mathrm{FU}=1$ are altered, and shifted towards a greener type, and therefore, all figures and tables displaying aggregated quantities would need to be rebuilt. Classes 2 and higher would remain unaltered.

\section{Conclusions}

This work has performed for the first time a thorough evaluation of the hue angle and FU products over global oceanic waters. The projection of monthly climatological $\mathrm{R}_{\mathrm{rs}}$ of selected marine zones onto the $\mathrm{CIE}(\mathrm{x}, \mathrm{y})$ plane depicted a continuous trail, that formed a rather compact curved line 
for the oligotrophic zones, suggesting a good description using a single parameter (case 1) while the trail showed increasing spread as hue angle decreased, as expectable for case 2 waters. The FU scale falls short in describing optical variability of the oligotrophic zones, with all oligotrophic gyres shown as FU=1. For mid-latitude zones, coastal zones and productive seas, ranges encompassed two, three, up to even five FU classes. We showed that the FU scale can be expanded to better characterize variability in oligotrophic waters.

Considering the $\mathrm{FU}$ index as a clustering variable of satellite ocean color data allowed the $\mathrm{FU}$, providing a physical basis for the FU scale and allowing the association of water color to relevant parameters for primary production, ocean heating or visibility. This approach is methodologically different to that presented in Wang et al. (2019), which combined radiative transfer modelling and empirical relationships to relate $\mathrm{z}_{\mathrm{SD}}$ and $\mathrm{FU}$ data to modern IOPs.

The FU OWTs form a clear sequence from bluest to greenest waters, with increasing $C_{a}$, increasing $\mathrm{K}_{\mathrm{d}}$ and decreasing $\mathrm{z}_{\mathrm{SD}}$. As FU increases, so does the spread within each class, indicating an increasing optical diversity and decreasing representativeness of an average class. Comparatively, the classes proposed in Jackson et al. (2017) show similar characteristics except with a broader range for blue waters, a slight mismatch in color with respect to the FU classification, and three upper classes that do not add further dynamic range in the context of color (not brightness). Contrary to these two classifications, classes by Mélin and Vantrepotte (2015) and Wei et al. (2016) highlight $R_{r s}$ shape differences within the average marine waters and identify clusters of similar hue but different saturation.

The FU optical water types are a clearly ordered set in terms of the hue angle. Similar firstorder behavior was found for the global marine $R_{r s}$, which supported the definition of class memberships as functions proportional to the angular distances to the two nearest FU, having the properties of adding up to one at a given hue angle. This methodology sets the basis for an intuitive yet rigorous algorithm blending procedure.

Projection of a spectrum onto the $(x, y)$ plane has the limitation of being sensitive only to spectral information within the visible range, with the bands $412 \mathrm{~nm}$ and $670 \mathrm{~nm}$ already having a minimal weight. An expectable effect is the possible inability to respond to CDOM changes in marine waters that are independent to $C_{a}$. Any other outside this range is not detectable.

The direct relationships between color, transparency and phytoplankton are representative of average marine conditions and thus less frequent events are not represented. Examples of these situations are glacial flour-rich lakes or marine coccolithophore blooms. In both cases, turbidity is much higher than described by the average relationships shown here, given their hue angle. This anomaly is caused by the kind of particles present in the water, that highly increase the brightness and saturation of the spectrum without increasing the hue angle very much, compared to average marine cases. If such anomalous spectra are to be included in optical water types, they can be manually extracted from selected images (Moore et al. 2012).

In this article, we have studied the global traits of optical variability. FU classes showed internal variability that is expected to relate to different zones of the ocean. Future work could aim at clustering data within each FU class and identify similarities and differences between these "secondorder classes" within each FU. This approach would provide more insights of optical variability within distinct optical ranges in the world's oceans.

In addition to all the characteristics of any OWT classification (i.e., tool for uncertainty assessment and for variability monitoring), the FU scale adds the advantage of being linkable to historic measurements. This approach can allow us to continue to monitor long-term change in optical diversity over the global ocean color by stitching together in situ FU data collected over the 
past century with the satellite era. The approach can be used to bridge, in a consistent manner, satellite data from two different periods (e.g. 1970-80's CZCS and 1997-onward) using in situ FU data over the two periods. The FU climatology can be the basis for quality control of in-situ global FU data. For instance, in-situ values that would be highly off the climatological values could be flagged. Nevertheless, any study linking satellite FU to historic in-situ FU from visual observation will need to deal with the issue that FU observations over a Secchi disk appear greener than those over an optically deep water column (Pitarch 2017). Another issue is that satellite FU are calculated from bidirectionally-corrected $R_{r s}$, whereas in-situ FU come from upwelling radiance in air, for any illumination conditions. An added difficulty is that archived FU data provide no information on the atmospheric conditions. This is likely to add unknown biases, whose effect will need to be tested, potentially using coupled atmospheric and marine optical modelling.

Increasingly, bio-optical modules are being added to global biogeochemical models (Baird et al. 2016; Dutkiewicz et al. 2019) to look at impacts of climate change. Our approach can be integrated and used to verify early 20th century model simulations through comparison with in situ FU data collected at the time.

As a final remark, the FU scale and the hue angle are powerful quantities for outreach and educational purposes, easy to understand by a broader audience. They are intuitive quantities that help provide clear messages to spread scientific developments to mass media (McGrath 2019) and are ideal for developing citizen-science projects and events on water quality and ocean state, and engaging citizens in becoming actively involved in environmental monitoring (Citclops 2015). For these reasons, this topic will deserve further attention by the community in the coming years.

\section{Acknowledgements}

The research leading to these results has received partial funding from the 'Coastal Ocean Darkening' project funded by the Ministry for Science and Culture of Lower Saxony, Germany (VWZN3175).This is a contribution to the Ocean Colour Climate Change Initiative of the European Space Agency. RJWB is supported by the UK National Centre for Earth Observation. This work continues research initiated by Marcel Wernand on historic optical observing methods, whose determination and meticulous work has inspired the rediscovery of these by the community, leading to new data and insights into ocean optics. 


\section{Annex A}

Table A1 Percentiles $25^{\text {th }}, 50^{\text {th }}$ (median, bold) and $75^{\text {th }}$ of the global climatological $R_{r s}$ associated to every FU, times 1000 . The median values are defined as the FU- $\mathrm{R}_{\mathrm{rs}}$ OWTs. The normalized root mean square deviation (RMS difference over the mean value) is provided, as useful to show the indicating ability of the FU classes.

\begin{tabular}{|c|c|c|c|c|c|c|c|c|c|c|c|c|}
\hline & FU & 1 & 2 & 3 & 4 & 5 & 6 & 7 & 8 & 9 & 10 & 11 \\
\hline \multirow{4}{*}{ Rrs412 } & p25 & 11.016 & 7.6593 & 5.1896 & 3.0242 & 2.0882 & 1.8225 & 1.8049 & 1.8266 & 1.9182 & 1.9442 & 1.98 \\
\hline & p50 & 12.329 & 8.5122 & 6.2162 & 3.7662 & 2.617 & 2.4442 & 2.7722 & 2.9814 & 3.1359 & 3.0965 & 3.0594 \\
\hline & p75 & 13.974 & 9.3271 & 7.2776 & 4.7273 & 3.4246 & 3.6636 & 4.7479 & 5.2498 & 5.3063 & 4.9788 & 4.6239 \\
\hline & NRMSD & 1.015 & 1.01 & 1.0299 & 1.0651 & 1.1313 & 1.2469 & 1.2781 & 1.2447 & 1.2227 & 1.234 & 1.2113 \\
\hline \multirow{4}{*}{ Rrs443 } & p25 & 8.6404 & 6.2396 & 4.6492 & 3.1004 & 2.2515 & 1.9935 & 1.938 & 1.8995 & 1.9182 & 1.8737 & 1.8876 \\
\hline & p50 & 9.5296 & 6.8382 & 5.3101 & 3.6612 & 2.7782 & 2.7521 & 3.2024 & 3.4217 & 3.6301 & 3.5116 & 3.4768 \\
\hline & p75 & 10.509 & 7.4576 & 6.0966 & 4.3471 & 3.4871 & 4.2209 & 5.7998 & 6.5377 & 6.5895 & 5.974 & 5.6509 \\
\hline & NRMSD & 1.0109 & 1.0089 & 1.022 & 1.0538 & 1.1401 & 1.2967 & 1.3244 & 1.2772 & 1.2559 & 1.2494 & 1.2138 \\
\hline \multirow{3}{*}{ Rrs490 } & p25 & 5.8257 & 5.1678 & 4.3647 & 3.3709 & 2.7683 & 2.7701 & 3.0024 & 3.1455 & 3.3634 & 3.4142 & 3.3941 \\
\hline & p50 & 6.0535 & 5.4362 & 4.8643 & 3.8807 & 3.3763 & 3.9066 & 5.0333 & 5.5882 & 5.9554 & 5.8866 & 5.9312 \\
\hline & p75 & 6.2898 & 5.8069 & 5.5613 & 4.5166 & 4.273 & 6.1066 & 8.6594 & 9.6985 & 9.8765 & 9.189 & 8.8311 \\
\hline & NRMSD & 1.0019 & 1.0056 & 1.0183 & 1.0553 & 1.1491 & 1.2867 & 1.2829 & 1.2257 & 1.1976 & 1.1857 & 1.1601 \\
\hline \multirow{3}{*}{ Rrs510 } & p25 & 3.3605 & 3.3238 & 3.197 & 2.9027 & 2.7305 & 2.8937 & 3.2379 & 3.5284 & 3.8503 & 3.9345 & 3.9762 \\
\hline & p50 & 3.452 & 3.5105 & 3.5085 & 3.2798 & 3.206 & 3.8828 & 5.1885 & 5.936 & 6.4656 & 6.4735 & 6.6164 \\
\hline & p75 & 3.5417 & 3.8112 & 4.062 & 3.7775 & 3.942 & 5.8699 & 8.7139 & 10.103 & 10.484 & 9.9153 & 9.679 \\
\hline & NRMSD & 1.0014 & 1.0073 & 1.0157 & 1.043 & 1.1201 & 1.2667 & 1.2738 & 1.2147 & 1.1877 & 1.1758 & 1.1492 \\
\hline \multirow{4}{*}{ Rrs555 } & $\mathrm{p} 25$ & 1.3324 & 1.6903 & 1.9171 & 1.9069 & 2.0619 & 2.642 & 3.4487 & 4.1836 & 4.8803 & 5.3384 & 5.7549 \\
\hline & p50 & 1.4244 & 1.7983 & 2.1416 & 2.3059 & 2.6044 & 3.6976 & 5.677 & 7.1528 & 8.3388 & 8.8767 & 9.5032 \\
\hline & p75 & 1.5162 & 1.9409 & 2.5022 & 2.8087 & 3.363 & 5.796 & 9.9198 & 12.528 & 13.643 & 13.424 & 13.614 \\
\hline & NRMSD & 1.005 & 1.009 & 1.0228 & 1.067 & 1.1588 & 1.3068 & 1.287 & 1.2232 & 1.1906 & 1.1746 & 1.1417 \\
\hline \multirow{3}{*}{ Rrs670 } & $\mathrm{p} 25$ & 0.11575 & 0.20267 & 0.27558 & 0.33067 & 0.42649 & 0.5958 & 0.86331 & 1.1943 & 1.6244 & 2.0202 & 2.434 \\
\hline & p50 & 0.1381 & 0.23461 & 0.31794 & 0.39102 & 0.51361 & 0.79461 & 1.3832 & 2.1484 & 2.9874 & 3.6123 & 4.2298 \\
\hline & p75 & 0.15994 & 0.27929 & 0.36992 & 0.46855 & 0.65003 & 1.2289 & 2.6012 & 4.2451 & 5.4503 & 6.0559 & 6.7456 \\
\hline
\end{tabular}




\begin{tabular}{|c|c|c|c|c|c|c|c|c|c|c|c|c|}
\hline & NRMSD & 1.2668 & 1.0955 & 1.1143 & 1.1665 & 1.2474 & 1.3947 & 1.4083 & 1.324 & 1.2779 & 1.2483 & 1.2086 \\
\hline & FU & 12 & 13 & 14 & 15 & 16 & 17 & 18 & 19 & 20 & 21 & \\
\hline \multirow{3}{*}{ Rrs412 } & p25 & 2.1197 & 2.0982 & 1.822 & 1.6582 & 1.4503 & 1.2418 & 2.4601 & 2.6281 & 2.6736 & 2.726 & \\
\hline & p50 & 3.2555 & 3.1541 & 2.8373 & 2.4001 & 2.2218 & 2.0205 & 3.7438 & 4.5718 & 4.0693 & 4.09 & \\
\hline & p75 & 4.7566 & 4.6344 & 4.4183 & 4.0482 & 4.3232 & 4.0885 & 6.3204 & 6.8928 & 5.9646 & 6.3058 & \\
\hline & NRMSD & 1.1802 & 1.2483 & 1.3069 & 1.3969 & 1.4731 & 1.4947 & 1.3101 & 1.3621 & 1.5667 & 1.3586 & \\
\hline \multirow{4}{*}{ Rrs443 } & p25 & 2.0314 & 2.0856 & 1.7557 & 1.6059 & 1.3862 & 1.2079 & 1.121 & 1.3204 & 1.3676 & 1.9248 & \\
\hline & p50 & 3.8131 & 3.4769 & 2.9685 & 2.3936 & 1.9916 & 1.6222 & 1.7061 & 2.0445 & 2.3149 & 2.703 & \\
\hline & p75 & 5.7045 & 5.4325 & 4.7963 & 3.6119 & 3.182 & 2.3284 & 2.7541 & 3.1021 & 3.4514 & 3.8792 & \\
\hline & NRMSD & 1.187 & 1.1635 & 1.1871 & 1.1873 & 1.2276 & 1.235 & 1.2388 & 1.1704 & 1.1819 & 1.1378 & \\
\hline \multirow{3}{*}{ Rrs490 } & p25 & 3.5876 & 3.5896 & \begin{tabular}{|l|l|}
3.1898 \\
\end{tabular} & 2.9658 & 2.7174 & 2.4875 & 2.1467 & 2.3665 & 2.4254 & 2.6363 & \\
\hline & p50 & 6.4911 & 6.0634 & 5.1716 & 4.3417 & 3.6841 & 3.2129 & 2.9514 & 3.4086 & 3.3791 & 3.8462 & \\
\hline & p75 & 9.0113 & 8.894 & 7.9498 & 6.2245 & 5.648 & 4.3436 & 4.3871 & 4.8753 & 5.4314 & 5.3633 & \\
\hline & NRMSD & 1.1419 & 1.1292 & \begin{tabular}{|l|}
1.1487 \\
\end{tabular} & 1.1446 & 1.1591 & 1.1561 & 1.1848 & \begin{tabular}{|l|}
1.1206 \\
\end{tabular} & 1.1458 & 1.1189 & \\
\hline \multirow{4}{*}{ Rrs510 } & p25 & 4.1664 & 4.0729 & 3.7157 & 3.5196 & 3.1648 & 2.8301 & 2.4476 & 2.7354 & 2.6382 & 2.7343 & \\
\hline & p50 & 7.2172 & 6.9098 & 5.8867 & 4.8914 & 4.2153 & 3.6276 & 3.3718 & \begin{tabular}{|l}
3.5378 \\
\end{tabular} & 3.6699 & 3.7573 & \\
\hline & p75 & 9.9667 & 9.9684 & 8.9431 & 6.9559 & 6.2093 & 4.7851 & 4.8224 & 5.0719 & 5.2375 & 5.0109 & \\
\hline & NRMSD & 1.1334 & 1.1221 & 1.1428 & 1.1374 & 1.1538 & 1.1494 & 1.1743 & \begin{tabular}{|l|}
1.1067 \\
\end{tabular} & 1.1201 & 1.0986 & \\
\hline \multirow{4}{*}{ Rrs555 } & p25 & 6.1767 & 6.3959 & 5.522 & 5.1835 & 5.0568 & 4.837 & 3.8859 & 3.4678 & 2.8018 & 2.7691 & \\
\hline & p50 & \begin{tabular}{|l|}
10.635 \\
\end{tabular} & 10.605 & 9.0728 & 7.5442 & 6.7783 & 6.1927 & 4.91 & \begin{tabular}{|l|l|} 
\\
\end{tabular} & 4.5105 & 3.8885 & \\
\hline & p75 & 14.285 & 14.794 & 13.832 & 10.829 & 9.83 & 8.0257 & 7.2041 & 6.5843 & 6.0834 & 5.3058 & \\
\hline & NRMSD & 1.1261 & 1.1169 & 1.1403 & 1.1368 & 1.149 & 1.1259 & 1.1621 & 1.1217 & 1.1354 & 1.1191 & \\
\hline \multirow{4}{*}{ Rrs670 } & p25 & 3.0533 & 3.5946 & 3.7649 & 4.2492 & 4.6733 & 5.1744 & 4.5067 & 5.1961 & 5.0864 & 5.9692 & \\
\hline & p50 & 5.4807 & 5.9337 & 5.955 & 6.0316 & 6.1105 & 6.3767 & 6.2091 & 6.7818 & 7.5231 & 9.2302 & \\
\hline & p75 & 7.966 & 8.8898 & 9.2645 & 8.6642 & 9.1095 & 8.4577 & 9.1568 & 9.8671 & 10.705 & 14.236 & \\
\hline & NRMSD & 1.1761 & 1.1506 & 1.153 & 1.1403 & 1.1605 & 1.1781 & 1.2532 & 1.178 & 1.1338 & 1.1663 & \\
\hline
\end{tabular}


Table A2 Percentiles $25^{\text {th }}, 50^{\text {th }}$ (median, bold) and $75^{\text {th }}$ of the global climatological $K_{d}$ associated to every FU, times 10 . The normalized root mean square deviation (RMS difference over the mean value) is provided, as useful to show the indicating ability of the FU classes.

\begin{tabular}{|c|c|c|c|c|c|c|c|c|c|c|c|c|}
\hline & FU & 1 & 2 & 3 & 4 & 5 & 6 & 7 & 8 & 9 & 10 & 11 \\
\hline \multirow{4}{*}{ Kd412 } & p25 & 0.23311 & 0.40351 & 0.61743 & 0.99557 & 1.5997 & 2.5404 & 3.7856 & 5.26 & 6.923 & 8.5758 & 10.478 \\
\hline & p50 & 0.27214 & 0.45567 & 0.68526 & 1.1108 & 1.7946 & 2.9014 & 4.5755 & 6.8669 & 9.3814 & 11.416 & 13.631 \\
\hline & p75 & 0.31207 & 0.50638 & 0.77756 & 1.2672 & 2.0607 & 3.4524 & 6.0573 & 9.0605 & 11.865 & 14.359 & 17.237 \\
\hline & NRMSD & 2.1856 & 1.0975 & 1.1303 & 1.1414 & 1.1293 & 1.1157 & 1.0993 & 1.0845 & 4.1994 & 1.572 & 1.2451 \\
\hline \multirow{3}{*}{ Kd443 } & p25 & 0.21923 & 0.37833 & 0.56149 & 0.84521 & 1.3034 & 2.0496 & 3.2057 & 4.7788 & 6.466 & 8.4062 & 10.385 \\
\hline & p50 & 0.25397 & 0.42218 & 0.61886 & 0.93445 & 1.4466 & 2.3205 & 3.7689 & 5.6536 & 7.7139 & 9.7158 & \begin{tabular}{|l|}
11.796 \\
\end{tabular} \\
\hline & NRMSD & 2.1759 & 1.106 & 1.155 & 1.1792 & 1.1727 & 1.1363 & 1.0974 & 1.0693 & 5.9628 & 2.3567 & 2.4504 \\
\hline \multirow{4}{*}{ Kd490 } & $\mathrm{p} 25$ & 0.2391 & 0.34442 & 0.46394 & 0.62704 & 0.88519 & 1.3046 & 2.0014 & 2.8814 & 3.8921 & 5.0359 & 6.2936 \\
\hline & p50 & 0.26435 & 0.37208 & 0.50163 & 0.69349 & 0.99186 & 1.5046 & 2.424 & 3.7216 & 5.1437 & 6.4702 & 7.8106 \\
\hline & p75 & 0.2886 & 0.40154 & 0.54818 & 0.77454 & 1.1385 & 1.8514 & 3.4808 & 5.4275 & 7.1152 & 8.381 & \begin{tabular}{|l|}
9.7 \\
\end{tabular} \\
\hline & NRMSD & 1.894 & 1.1119 & 1.1842 & 1.2193 & 1.2177 & 1.1864 & 1.1463 & 1.1149 & 3.5436 & 2.0634 & 1.7912 \\
\hline \multirow{3}{*}{ Kd510 } & p25 & 0.34987 & 0.44773 & 0.55419 & 0.65786 & 0.84909 & 1.2106 & 1.7937 & 2.5411 & 3.4007 & 4.3922 & 5.5362 \\
\hline & p75 & 0.3942 & 0.50367 & 0.6258 & 0.80303 & 1.096 & 1.7272 & 3.2787 & 5.1116 & 6.6317 & 7.7952 & 8.9982 \\
\hline & NRMSD & 1.5937 & 1.0944 & 1.1573 & 1.2162 & 1.2352 & 1.2046 & 1.1629 & 1.1312 & 3.5052 & 2.0447 & 1.7857 \\
\hline \multirow{4}{*}{ Kd555 } & p25 & 0.64078 & 0.67407 & 0.71933 & 0.78785 & 0.92853 & 1.1878 & 1.6027 & 2.1107 & 2.7101 & 3.4177 & 4.227 \\
\hline & p50 & 0.6477 & 0.68427 & 0.73637 & 0.8252 & 0.99168 & 1.316 & 1.8829 & 2.8126 & 3.8351 & 4.6947 & 5.5864 \\
\hline & p75 & 0.655 & 0.69618 & 0.75918 & 0.87064 & 1.0816 & 1.5465 & 2.8237 & 4.3112 & 5.5437 & 6.4191 & \begin{tabular}{|l|}
7.3657 \\
\end{tabular} \\
\hline & NRMSD & 1.3502 & 1.0747 & 1.1333 & 1.1977 & 1.2257 & 1.2109 & 1.1726 & 1.1474 & 3.0054 & 2.0954 & 1.7355 \\
\hline \multirow{5}{*}{ Kd670 } & $\mathrm{p} 25$ & 4.4218 & 4.4374 & 4.4523 & 4.4637 & 4.4957 & 4.5851 & 4.8157 & 5.7764 & 6.4168 & 6.978 & \begin{tabular}{|l}
7.496 \\
\end{tabular} \\
\hline & p50 & 4.4257 & 4.4421 & 4.4622 & 4.4848 & 4.5303 & 4.7031 & 5.6579 & 6.403 & 7.1268 & \begin{tabular}{|l|}
7.7938 \\
\end{tabular} & 8.4176 \\
\hline & p75 & 4.43 & 4.4483 & 4.4776 & 4.5122 & 4.5917 & 5.4211 & 6.4101 & 7.4338 & 8.3182 & 8.9809 & 9.7265 \\
\hline & NRMSD & 1.0011 & 1.0007 & 1.0008 & 1.0022 & 1.0074 & 1.0198 & 1.0247 & 1.036 & 1.1755 & 1.1854 & 1.1131 \\
\hline & FU & 12 & 13 & 14 & 15 & 16 & 17 & 18 & 19 & 20 & 21 & \\
\hline
\end{tabular}




\begin{tabular}{|c|c|c|c|c|c|c|c|c|c|c|c|}
\hline \multirow{4}{*}{ Kd412 } & p25 & 12.561 & 15.06 & 17.503 & 20.374 & 23.062 & 24.332 & 14.705 & 14.778 & 20.097 & 28.152 \\
\hline & p50 & 17.002 & 19.704 & 23.33 & 28.573 & 35.881 & 44.401 & 25.318 & 30.187 & 33.621 & 47.229 \\
\hline & p75 & 21.107 & 24.732 & 30.012 & 36.348 & 46.893 & 60.39 & 44.505 & 48.403 & 45.808 & 81.003 \\
\hline & NRMSD & 1.6738 & 1.3966 & 1.3086 & 1.156 & 1.214 & 1.2899 & 1.6725 & 1.3671 & 1.4809 & 1.2808 \\
\hline \multirow{4}{*}{ Kd443 } & p25 & 12.965 & 15.36 & 18.926 & 24.121 & 30.631 & 39.774 & 35.749 & 35.418 & 34.581 & 40.869 \\
\hline & p50 & 14.327 & 17.147 & 21.194 & 26.663 & 35.124 & 47.237 & 46.933 & 46.74 & 44.33 & 57.268 \\
\hline & p75 & 16.454 & 19.494 & 23.608 & 29.666 & 39.764 & 54.438 & 59.792 & 64.021 & 61.65 & 89.374 \\
\hline & NRMSD & 1.9455 & 1.3505 & 1.1479 & 1.1199 & 1.1845 & 1.2116 & 1.4048 & 1.1932 & 1.2071 & 1.2511 \\
\hline \multirow{4}{*}{ Kd490 } & p25 & 8.1397 & 9.8644 & 11.846 & \begin{tabular}{|l|}
14.858 \\
\end{tabular} & 18.641 & 23.254 & 23.332 & 24.239 & 25.039 & 29.665 \\
\hline & p50 & 9.5778 & 11.469 & 13.454 & 16.447 & 20.608 & 26.404 & 27.609 & 28.837 & 30.027 & 39.258 \\
\hline & p75 & 11.66 & 13.589 & 15.788 & 18.134 & 22.661 & 29.649 & 31.286 & 35.38 & 38.47 & 60.902 \\
\hline & NRMSD & 1.6288 & 1.3164 & 1.1192 & 1.0558 & 1.173 & 1.1608 & 1.3247 & 1.1662 & 1.1121 & 1.2154 \\
\hline \multirow{4}{*}{ Kd510 } & $\mathrm{p} 25$ & 7.2671 & 8.7353 & 10.515 & 13.28 & 16.726 & 20.955 & 21.711 & 22.538 & 23.514 & 28.739 \\
\hline & p50 & 8.764 & 10.393 & 12.2 & 14.763 & 18.653 & 23.818 & 24.858 & 26.199 & 28.209 & 37.063 \\
\hline & p75 & 10.886 & 12.618 & 14.673 & 16.834 & 20.62 & 26.943 & 28.686 & 32.529 & 35.651 & 59.132 \\
\hline & NRMSD & 1.7645 & 1.4163 & 1.1319 & 1.0577 & 1.1734 & 1.1663 & 1.3169 & 1.1672 & 1.1115 & 1.2 \\
\hline \multirow{4}{*}{ Kd555 } & $\mathrm{p} 25$ & 5.5589 & 6.5013 & 7.7544 & 9.5196 & 11.811 & 14.749 & 15.731 & 18.549 & 21.907 & 27.284 \\
\hline & p50 & 6.8638 & 8.0561 & 9.3377 & 10.992 & 13.332 & 16.398 & 18.191 & 22.279 & 25.468 & 36.082 \\
\hline & p75 & 8.8048 & 10.308 & 12.025 & 13.463 & 16.208 & 18.736 & 22.956 & 27.761 & 29.868 & 54.655 \\
\hline & NRMSD & 2.0277 & 1.5756 & 1.162 & 1.077 & 1.3994 & 1.2599 & 1.3941 & 1.1584 & 1.1231 & 1.1923 \\
\hline \multirow{4}{*}{ Kd670 } & $\mathrm{p} 25$ & 8.1899 & 8.8514 & 9.5956 & 10.713 & 12.215 & 13.912 & 13.053 & 12.815 & 12.921 & 14.104 \\
\hline & p50 & 9.3909 & 10.147 & 10.884 & 11.926 & 13.507 & 15.523 & 15.28 & 15.513 & 15.755 & 17.549 \\
\hline & p75 & 10.779 & 11.724 & 12.911 & 13.711 & 15.238 & 17.172 & 17.556 & 19.369 & 19.596 & 25.417 \\
\hline & NRMSD & 1.0907 & 1.0821 & 1.0406 & 1.0278 & 1.0536 & 1.1009 & 1.1981 & 1.1115 & 1.0671 & 1.1282 \\
\hline
\end{tabular}


Table A3 Percentiles $25^{\text {th }}, 50^{\text {th }}$ (median, bold) and $75^{\text {th }}$ of the global climatological Secchi disk depth ( $\mathrm{m}$ ) associated to every FU. The normalized root mean square deviation (RMS difference over the mean value) is provided, as useful to show the indicating ability of the FU classes.

\begin{tabular}{|c|c|c|c|c|c|c|c|c|c|c|c|c|}
\hline & FU & 1 & 2 & 3 & 4 & 5 & 6 & 7 & 8 & 9 & 10 & 11 \\
\hline \multirow{5}{*}{$\mathrm{z}_{\mathrm{SD}}$} & p25 & 32.372 & 23.287 & 17.087 & 12.224 & 8.8563 & 6.0818 & 3.2734 & 2.1256 & 1.6475 & 1.4228 & 1.2387 \\
\hline & p50 & \begin{tabular}{|l|}
36.328 \\
\end{tabular} & 25.121 & 18.668 & 13.626 & 9.9518 & \begin{tabular}{|l|}
7.1701 \\
\end{tabular} & 4.9728 & 3.3197 & 2.4166 & 1.9708 & 1.664 \\
\hline & p75 & 41.942 & 27.129 & 20.175 & 15.061 & 11.156 & 8.0045 & 5.8624 & 4.444 & 3.4578 & 2.7442 & 2.2155 \\
\hline & NRMSD & 1.0151 & 1.0052 & 1.0079 & 1.0151 & 1.0222 & 1.0379 & 1.0627 & 1.078 & 1.0838 & 1.0804 & 1.0796 \\
\hline & $\mathrm{FU}$ & 12 & 13 & 14 & 15 & 16 & 17 & 18 & 19 & 20 & 21 & \\
\hline \multirow{3}{*}{$\mathrm{z}_{\mathrm{SD}}$} & $\mathrm{p} 25$ & 1.0407 & 0.90981 & 0.79518 & 0.72428 & 0.62745 & 0.54247 & 0.53398 & 0.48152 & 0.47913 & 0.35545 & \\
\hline & p75 & 1.6804 & 1.4332 & 1.2139 & 1.0038 & 0.82917 & 0.6997 & 0.78487 & 0.79595 & 0.7583 & \begin{tabular}{|l|}
0.6962 \\
\end{tabular} & \\
\hline & NRMSD & 1.0779 & 1.0647 & 1.0447 & 1.0332 & 1.0326 & 1.042 & 1.0663 & 1.0708 & 1.0581 & 1.1005 & \\
\hline
\end{tabular}

Table A4 Percentiles $25^{\text {th }}, 50^{\text {th }}$ (median, bold) and $75^{\text {th }}$ of the global climatological chlorophyll concentration (mg $\mathrm{m}^{-3}$ ) associated to every FU, times 10 . The normalized root mean square deviation (RMS difference over the mean value) is provided, as useful to show the indicating ability of the FU classes.

\begin{tabular}{|c|c|c|c|c|c|c|c|c|c|c|c|c|}
\hline & FU & 1 & 2 & 3 & 4 & 5 & 6 & 7 & 8 & 9 & 10 & 11 \\
\hline \multirow{5}{*}{$C_{a}$} & p25 & 0.46307 & 1.2509 & 2.1864 & 4.425 & 8.7668 & 13.94 & 20.894 & 28.132 & 33.139 & 38.031 & 42.706 \\
\hline & p50 & 0.6565 & 1.4427 & 2.596 & 5.4827 & 11.118 & 17.455 & 25.262 & 33.517 & 39.333 & 46.663 & 54.02 \\
\hline & p75 & 0.84922 & 1.6638 & 3.1611 & 6.9951 & 14.551 & 22.852 & 31.987 & 41.528 & 49.975 & 63.165 & 72.947 \\
\hline & NRMSD & 1.1273 & 1.0394 & 1.1318 & 1.1294 & 1.1245 & 1.1211 & 1.0937 & 1.088 & 1.092 & 1.1066 & 1.1244 \\
\hline & FU & 12 & 13 & 14 & 15 & 16 & 17 & 18 & 19 & 20 & 21 & \\
\hline \multirow{4}{*}{$\mathrm{C}_{\mathrm{a}}$} & p25 & 45.197 & 50.166 & 55.438 & 61.792 & 69.495 & 79.281 & 30.209 & 22.509 & 15.373 & 10.27 & \\
\hline & p50 & 57.852 & \begin{tabular}{|l|}
63.985 \\
\end{tabular} & 66.21 & 72.651 & 83.516 & \begin{tabular}{|l|}
111.07 \\
\end{tabular} & 93.542 & 46.123 & 32.199 & 16.328 & \\
\hline & p75 & 76.392 & 89.26 & 86.299 & 86.811 & 106.12 & 140.47 & 133.3 & 105.66 & 67.183 & 36.89 & \\
\hline & NRMSD & 1.164 & 1.1949 & 1.1835 & 1.1468 & 1.1179 & 1.1052 & 1.2145 & 1.3589 & 1.4264 & 1.6297 & \\
\hline
\end{tabular}




\section{References}

Al-Naimi, N., Raitsos, D., Ben-Hamadou, R., \& Soliman, Y. (2017). Evaluation of satellite retrievals of chlorophyll-a in the Arabian Gulf. Remote Sensing, 9, 301

Baird, M.E., Cherukuru, N., Jones, E., Margvelashvili, N., Mongin, M., Oubelkheir, K., Ralph, P.J., Rizwi, F., Robson, B.J., Schroeder, T., Skerratt, J., Steven, A.D.L., \& Wild-Allen, K.A. (2016). Remote-sensing reflectance and true colour produced by a coupled hydrodynamic, optical, sediment, biogeochemical model of the Great Barrier Reef, Australia: Comparison with satellite data. Environmental Modelling \& Software, $78,79-96$

Boyce, D.G., Lewis, M., \& Worm, B. (2012). Integrating global chlorophyll data from 1890 to 2010. Limnology and Oceanography: Methods, 10, 840-852

Brock, J.C., \& McClain, C.R. (1992). Interannual variability in phytoplankton blooms observed in the northwestern Arabian Sea during the southwest monsoon. Journal of Geophysical Research: Oceans, $97,733-750$

Burchard, H., Bolding, K., \& Ruiz-Villarreal, M. (1999). GOTM-A General Ocean Turbulence Model, Theory, Implementation and Test cases. In. Ispra, Italy: Joint Research Centre, Space Applications Institute, European Commission

Busch, J., Bardaji, R., Ceccaroni, L., Friedrichs, A., Piera, J., Simon, C., Thijsse, P., Wernand, M., van der Woerd, H., \& Zielinski, O. (2016). Citizen Bio-Optical Observations from Coast- and Ocean and Their Compatibility with Ocean Colour Satellite Measurements. Remote Sensing, 8, 879

Cahill, B., Schofield, O., Chant, R., Wilkin, J., Hunter, E., Glenn, S., \& Bissett, P. (2008). Dynamics of turbid buoyant plumes and the feedbacks on near-shore biogeochemistry and physics. Geophysical Research Letters, 35

Citclops (2015). Citclops (Citizens' Observatory for Coast and Ocean Optical Monitoring). In

Colella, S., Falcini, F., Rinaldi, E., Sammartino, M., \& Santoleri, R. (2016). Mediterranean Ocean Colour Chlorophyll Trends. PLOS ONE, 11, e0155756

Dave, A.C., \& Lozier, M.S. (2015). The impact of advection on stratification and chlorophyll variability in the equatorial Pacific. Geophysical Research Letters, 42, 4523-4531

Dogliotti, A.I., Ruddick, K., \& Guerrero, R. (2016). Seasonal and inter-annual turbidity variability in the Río de la Plata from 15 years of MODIS: El Niño dilution effect. Estuarine, Coastal and Shelf Science, $182,27-39$

Dutkiewicz, S., Hickman, A.E., Jahn, O., Henson, S., Beaulieu, C., \& Monier, E. (2019). Ocean colour signature of climate change. Nature Communications, 10, 578

Forel, F.A. (1890). Une nouvelle forme de la gamme de couleur pour l'étude de l'eau des lacs. Archives des sciences physiques et naturelles/Societe de physique et d'histoire naturelle de geneve, 6 , 25

Grant, M., Jackson, T., Chuprin, A., Sathyendranath, S., Zühlke, M., Storm, T., Boettcher, M., \& Fomferra, N. (2015). Ocean Colour Climate Change Initiative (OC_CCI)-Phase Two. Product User Guide. D3.4 PUG, Issue:2.0.5. In 
He, X., Bai, Y., Pan, D., Chen, C.T.A., Cheng, Q., Wang, D., \& Gong, F. (2013). Satellite views of the seasonal and interannual variability of phytoplankton blooms in the eastern China seas over the past 14 yr (1998\&ndash;2011). Biogeosciences, 10, 4721-4739

Hu, C., Lee, Z., \& Franz, B. (2012). Chlorophyll aalgorithms for oligotrophic oceans: A novel approach based on three-band reflectance difference. Journal of Geophysical Research: Oceans, 117

Jackson, T., Sathyendranath, S., \& Mélin, F. (2017). An improved optical classification scheme for the Ocean Colour Essential Climate Variable and its applications. Remote Sensing of Environment, 203, 152-161

Jafar-Sidik, M., Bowers, D.G., \& Griffiths, J.W. (2018). Remote sensing observations of ocean colour using the traditional Forel-Ule scale. Estuarine, Coastal and Shelf Science

Jerlov, N.G. (1976). Marine optics. Elsevier

Kaushal, H., \& Kaddoum, G. (2016). Underwater Optical Wireless Communication. IEEE Access, 4, 1518-1547

Kim, S.-W., Saitoh, S.-i., Ishizaka, J., Isoda, Y., \& Kishino, M. (2000). Temporal and Spatial Variability of Phytoplankton Pigment Concentrations in the Japan Sea Derived from CZCS Images. Journal of Oceanography, 56, 527-538

Kopelevich, O.V., Burenkov, V.I., Ershova, S.V., Sheberstov, S.V., \& Evdoshenko, M.A. (2004). Application of SeaWiFS data for studying variability of bio-optical characteristics in the Barents, Black and Caspian Seas. Deep Sea Research Part II: Topical Studies in Oceanography, 51, 1063-1091

Kubryakov, A.A., Stanichny, S.V., Zatsepin, A.G., \& Kremenetskiy, V.V. (2016). Long-term variations of the Black Sea dynamics and their impact on the marine ecosystem. Journal of Marine Systems, 163, 80-94

Lee, Z., Carder, K.L., \& Arnone, R.A. (2002). Deriving inherent optical properties from water color: a multiband quasi-analytical algorithm for optically deep waters. Applied Optics, 41, 5755-5772

Lee, Z., \& Hu, C. (2006). Global distribution of Case-1 waters: An analysis from SeaWiFS measurements. Remote Sensing of Environment, 101, 270-276

Lee, Z., Hu, C., Shang, S., Du, K., Lewis, M., Arnone, R., \& Brewin, R. (2013). Penetration of UV-visible solar radiation in the global oceans: Insights from ocean color remote sensing. Journal of Geophysical Research: Oceans, 118, 4241-4255

Lee, Z., Shang, S., Hu, C., Du, K., Weidemann, A., Hou, W., Lin, J., \& Lin, G. (2015). Secchi disk depth: A new theory and mechanistic model for underwater visibility. Remote Sensing of Environment, 169, 139-149

Lehmann, M., Nguyen, U., Allan, M., \& van der Woerd, H. (2018). Colour Classification of 1486 Lakes across a Wide Range of Optical Water Types. Remote Sensing, 10, 1273

Löptien, U., Eden, C., Timmermann, A., \& Dietze, H. (2009). Effects of biologically induced differential heating in an eddy-permitting coupled ocean-ecosystem model. Journal of Geophysical Research: Oceans, 114 
McGrath, M. (2019). Climate change: Blue planet will get even bluer as Earth warms. In: BBC News, Science \& Environment

Mélin, F., \& Vantrepotte, V. (2015). How optically diverse is the coastal ocean? Remote Sensing of Environment, 160, 235-251

Moore, T.S., Campbell, J.W., \& Dowell, M.D. (2009). A class-based approach to characterizing and mapping the uncertainty of the MODIS ocean chlorophyll product. Remote Sensing of Environment, $113,2424-2430$

Moore, T.S., Campbell, J.W., \& Hui, F. (2001). A fuzzy logic classification scheme for selecting and blending satellite ocean color algorithms. IEEE Transactions on Geoscience and Remote Sensing, 39, 1764-1776

Moore, T.S., Dowell, M.D., \& Franz, B.A. (2012). Detection of coccolithophore blooms in ocean color satellite imagery: A generalized approach for use with multiple sensors. Remote Sensing of Environment, 117, 249-263

Morel, A., Claustre, H., \& Gentili, B. (2010). The most oligotrophic subtropical zones of the global ocean: similarities and differences in terms of chlorophyll and yellow substance. Biogeosciences, 7 , 3139-3151

Morel, A., \& Prieur, L. (1977). Analysis of variations in ocean color. Limnology and Oceanography, 22, 709-722

Novoa, S., Wernand, M.R., \& van der Woerd, H.J. (2013). The Forel-Ule scale revisited spectrally: preparation protocol, transmission measurements and chromaticity. J. Eur. Opt. Soc.-Rapid publications, 8

Pitarch, J. (2017). Biases in ocean color over a Secchi disk. Optics Express, 25, A1124-A1131

Pitarch, J., Volpe, G., Colella, S., Krasemann, H., \& Santoleri, R. (2016). Remote sensing of chlorophyll in the Baltic Sea at basin scale from 1997 to 2012 using merged multi-sensor data. Ocean Sci., 12, 379-389

Richardson, K., Markager, S., Buch, E., Lassen, M.F., \& Kristensen, A.S. (2005). Seasonal distribution of primary production, phytoplankton biomass and size distribution in the Greenland Sea. Deep Sea Research Part I: Oceanographic Research Papers, 52, 979-999

Solonenko, M.G., \& Mobley, C.D. (2015). Inherent optical properties of Jerlov water types. Applied Optics, 54, 5392-5401

Trochta, J.T., Mouw, C.B., \& Moore, T.S. (2015). Remote sensing of physical cycles in Lake Superior using a spatio-temporal analysis of optical water typologies. Remote Sensing of Environment, 171, 149-161

Ule, W. (1892). Die bestimmung der Wasserfarbe in den Seen. Kleinere Mittheilungen. Dr. A. Petermanns Mittheilungen aus Justus Perthes geographischer Anstalt, 70-71

van der Woerd, H.J., \& Wernand, M.R. (2015). True Colour Classification of Natural Waters with Medium-Spectral Resolution Satellites: SeaWiFS, MODIS, MERIS and OLCI. Sensors, 15, 25663 
van der Woerd, H.J., \& Wernand, M.R. (2018). Hue-Angle Product for Low to Medium Spatial Resolution Optical Satellite Sensors. Remote Sensing, 10, 180

Wang, S., Lee, Z., Shang, S., Li, J., Zhang, B., \& Lin, G. (2019). Deriving inherent optical properties from classical water color measurements: Forel-Ule index and Secchi disk depth. Optics Express, 27, 76427655

Wang, S., Li, J., Zhang, B., Spyrakos, E., Tyler, A.N., Shen, Q., Zhang, F., Kuster, T., Lehmann, M.K., Wu, Y., \& Peng, D. (2018). Trophic state assessment of global inland waters using a MODIS-derived ForelUle index. Remote Sensing of Environment, 217, 444-460

Wei, J., Lee, Z., \& Shang, S. (2016). A system to measure the data quality of spectral remote-sensing reflectance of aquatic environments. Journal of Geophysical Research: Oceans, 121, 8189-8207

Wernand, M.R., Hommersom, A., \& van der Woerd, H.J. (2013a). MERIS-based ocean colour classification with the discrete Forel-Ule scale. Ocean Sci., 9, 477-487

Wernand, M.R., van der Woerd, H.J., \& Gieskes, W.W.C. (2013b). Trends in Ocean Colour and Chlorophyll Concentration from 1889 to 2000, Worldwide. PLOS ONE, 8, e63766

Yamaguchi, H., Kim, H.-C., Son, Y.B., Kim, S.W., Okamura, K., Kiyomoto, Y., \& Ishizaka, J. (2012). Seasonal and summer interannual variations of SeaWiFS chlorophyll a in the Yellow Sea and East China Sea. Progress in Oceanography, 105, 22-29 


\section{List of Figure Captions}

Fig. 1 The CIE standard observer color matching functions and the sum of all.

Fig. 2 The CIE 1931 color space in the $(x, y)$ coordinates. The coordinates of the $21 \mathrm{FU}$ colors after Novoa et al. (2013) are plotted as blue dots. The white point $W$ lays on $(1 / 3,1 / 3)$. An arbitrary spectrum is represented as point $P$, having polar coordinates $(\alpha, s)$ and laying between FU 3 and 4 .

Fig. 3 Discretization errors $\Delta x$ and $\Delta y$ in the computation of the $(x, y)$ coordinates as a function of $x^{\prime}$ for the IOCCG synthetized dataset, and corresponding fitted curves $c_{x}$ and $c_{y}$ (Table 1 ).

Fig. 4 Class membership functions as function of the hue angle.

Fig. 5 Distributions of the global climatological ESA-OC-CCI v2.0 $R_{r s}$ on the $(x, y)$ plane and in polar coordinates $(\alpha, s)$. Panel a1) log-density plot of $(x, y)$ distribution, with dot color indicating increasing data density. The moving median of $y$ for every $x$ as thick line, and the $25^{\text {th }}$ and $75^{\text {th }}$ percentiles as band boundaries, are plotted on top. a2) distribution of $x$. a3) distribution of $y$. a4) same band as panel $a 1)$ but setting the moving median of $y$ as ordinates origin. Panels b1) to b4) are equivalent to a1) to a4) but replacing $x$ by $s$ and $y$ by $\alpha$.

Fig. 6 Color maps of membership to class 2 and class 4 of the Mediterranean Sea for the climatological months of January, April, July and October, based on the ESA-OC-CCI v2.0 global climatological monthly $\mathrm{R}_{\mathrm{rs}}$.

Fig. 7 Global FU annual variability based on the ESA-OC-CCI v2.0 global climatological monthly $\mathrm{R}_{\mathrm{rs}}$.

Fig. 8 Remote-sensing reflectances corresponding to the first $10 \mathrm{FU}$ water types, obtained from the ESA-OC-CCl v2.0 global climatological monthly $R_{r s}$. Bold traces correspond to median values and bands extend between the $25^{\text {th }}$ and $75^{\text {th }}$ percentiles. Data of all classes can be found at Table A1.

Fig. 9 Fig. 19 Diffuse attenuation coefficient of downwelling irradiance of the first 9 FU classes, representing the median in bold line and the interval between the $25^{\text {th }}$ and $75^{\text {th }}$ percentiles in shaded band. For a complete description, the reader is referred to Table A2.

Fig. 10 Secchi disk depth histograms for each FU class. Each histogram aggregates all $z_{S D}$ derivations (Lee et al. 2015) from the ESA-OC-CCl v2.0 global climatological monthly $R_{r s}$ whose per-pixel associated FU have the same value. Statistical descriptors can be found in Table A3.

Fig. 11 Chlorophyll concentration histograms for each FU class. Each histogram aggregates all $\mathrm{C}_{\mathrm{a}}$ data the ESA-OC-CCl v2.0 global climatological monthly $C_{a}$ dataset whose per-pixel associated FU have the same value. Statistical descriptors can be found in Table A4.

Fig. 12 Chlorophyll concentration and Secchi disk depth box plots for each FU optical water type. The median is plotted as a dot inside a white circle. The interquartile range is delimited by the box around the median. Whiskers extend until three times the interquartile range below and above the first and third quartile, respectively. Data beyond the whiskers range are considered outliers and are plotted as dots. Statistical descriptors can be found in Tables A3-A4.

Fig. 13 Selected marine zones for the study of the seasonal color variability, over a map of the seriesaveraged chlorophyll-a concentration.

Fig. 14 Hue angle climatological annual variability of selected marine zones (see Fig. 13 and Table 6). The boundaries between consecutive FU classes are also indicated.

Fig. 15 Top panels show various OWTs projected in the $(x, y)$ plane (panel a1)) and in polar coordinates (panel b1)). The log-density plot of the coordinates derived from global climatological 
ESA-OC-CCl V2.0 $R_{r s}$ is shown, with the running median and the intervals determined by the $25^{\text {th }}$ and $75^{\text {th }}$ percentiles. Bottom panels represent the differences with respect to the running median.

Fig. 16 a) Polar coordinates ( $\alpha, s)$ of the 21 original FU classes, after Novoa et al. (2013), with derived spline curve and coordinates $\left(\alpha_{0}, \mathrm{~s}_{0}\right)$ of the new class $\mathrm{FU}_{0}$. b) The CIE 1931 color space in the $(x, y)$ coordinates, with the coordinates of the $21 \mathrm{FU}$ colors (2013) and the new FU $\mathrm{FU}_{0}$ (red dot).

Fig. 17 Global FU-extended annual variability based on the ESA-OC-CCI v2.0 climatological $\mathrm{R}_{\mathrm{rs}}$.

Fig. 18 Climatological chlorophyll-a maps for the months a) February and b) August. The contour lines are the boundaries between FU classes, including the newly developed $\mathrm{FU}_{0}$. 